\title{
Os desafios postos pela conservação da arquitetura moderna
}

Fernando Diniz Moreira*

\section{Resumo}

Nos últimos quinze ou vinte anos, assistimos a muitos casos de intervenções e restaurações de edifícios modernos, algumas bem sucedidas e outras que comprometeram irreversivelmente o valor dos bens. Essas intervenções, aliadas ao envelhecimento dos edifícios, colocam uma série de desafios que merecem uma reflexão mais cuidadosa.

Esses desafios referem-se a: 1) a própria atenção que arquitetos modernos dispensaram à funcionalidade que, conjugada com a rápida obsolescência funcional, trouxe dificuldades para a introdução de novos usos; 2) a dimensão material do edifício que inclui problemas como o uso de materiais novos sem um entendimento do desempenho destes no longo prazo, o uso de materiais tradicionais de forma inovadora, falhas na construção, problemas de detalhamento e o uso de materiais fabricados em série; 3) a necessidade de substituir sistemas infraestruturais (aquecimento, ar-condicionado, água, eletricidade, etc.) para que o edifício continue em uso, acarretando problemas de adequação; 4) a ausência de uma cultura da manutenção, que afeta diretamente os edifícios modernos; 5) a dificuldade de aceitação da pátina nesses edifícios, pois quase nunca é vista como um valor; 6) as dificuldades enfrentadas pelos conjuntos habitacionais que não conseguiram acompanhar $o$ envelhecimento, enriquecimento e empobrecimento de suas populações; e 7) os problemas existentes no reconhecimento e tombamento desta arquitetura. Apesar de esses desafios questionarem o arcabouço teórico da conservação, não acreditamos que a conservação da arquitetura moderna deva ser diferente da conservação de obras de um passado mais distante. Este texto, portanto, oferece uma revisão de literatura sobre os principais desafios em relação à conservação da arquitetura moderna, baseada sobretudo nos escritos de Susan McDonald e Theodore Prudon e nos anais dos principais seminários e encontros internacionais. 
Palavras-chave: Conservação da arquitetura moderna. Materiais de construção. Tombamento.

\title{
The challenges posed by the conservation of modern architecture
}

\begin{abstract}
In the last 15 or 20 years, many modern buildings were restored or renovated. Some of these restorations were very successful but others affected negatively and irreversibly the value of this heritage. These results, in additon to the weathering of modern buildings, pose a series of challenges which requires a more careful reflection.
\end{abstract}

These challenges refer to: 1) The careful attention modern architects paid to functional aspects in the definition of spatial arrangements, which, along the rapid functional obsolescence, makes the introduction of new uses more difficult; 2) the material dimension of the building which show problems created by the use of new materials without previous knowledge of its long-term perfomance, the use of traditional materials in new ways, construction faults, poor detailing and the use of prefabricated materials; 3 ) the need to replace servicing systems in order to keep the building in use; 4) the lack of a maintenance culture, which directly affects modern buildings, once considered to be maintenance-free; 5) the lack of acceptance of patina in modern architecture; 6 ) the difficulties faced by big housing blocks to adapt to the ageing of their residents, their enrichment or impoverishment; and 7) The problems in the recognition and listing of modern architecture. Although these issues challenge the theoretical background of the conservation, we do not believe that the conservation of modern architecture should be different from the conservation of architectural works from a more distant past. This paper, therefore, offers a literature survey about the main challenges brought by the conservation of modern architecture, based particularly on the writings Susan McDonald and Theodore Prudon and in the proceeding of the major seminars and conferences.

Keywords: Conservation of modern architecture. Building materials. Listing. 


\section{Introdução}

A conservação da arquitetura moderna traz novos desafios à disciplina da conservação. Esses desafios remetem não apenas às dimensões técnica e material do edifício, mas também ao arcabouço teórico da conservação. Além disso, a arquitetura moderna possui especificidades que devem ser consideradas em qualquer operação de conservação. Após construir um argumento sobre a necessidade de se conservar essa arquitetura, o trabalho elenca e caracteriza os principais desafios na conservação dessa arquitetura. Esses desafios referem-se a:

- A própria atenção que arquitetos modernos dispensaram à funcionalidade, conjugada com a rápida obsolescência funcional, o que traz dificuldades para se encontrar e introduzir novos usos.

- A dimensão material do edifício que inclui problemas, como o uso de materiais novos sem tradição construtiva, o uso de materiais tradicionais de forma inovadora, a falta de entendimento do desempenho dos materiais no longo prazo, as falhas na construção, os problemas de detalhamento e o uso de materiais fabricados em série.

- Os sistemas infraestruturais (aquecimento, arcondicionado, água, eletricidade, etc.), que precisam ser substituídos para que o edifício continue em uso, o que geralmente acarreta problemas de adequação.

- A ausência de uma cultura da manutenção, que afeta diretamente os edifícios modernos.

- A aceitação da pátina nos edifícios modernos, já que os materiais e as superfícies reluzentes das publicações de época fizeram com que os sinais deste envelhecimento não fossem compreendidos como um valor.

- Os desafios criados pela conservação de conjuntos habitacionais que não conseguiram acompanhar as transformações sociais, como o envelhecimento, o enriquecimento e o empobrecimento de suas populações.

- Os problemas existentes no reconhecimento e no tombamento.

A análise desses desafios será referenciada por estudos de casos. As fontes foram os escritos de Susan McDonald e Theodore Prudon, autores que se destacaram por sua reflexão sobre o tema, e os principais seminários e encontros internacionais sobre o tema, registrados em publicações como Modern Matters (1996), Structure 
and Style (1998), Preserving post war heritage (2001), Preserving the Recent Past I (1995) e II (2000), Curare II Moderno (2002), WHC Papers: Identification and Documentation of Modern Heritage (2003) e Architetura e Materiali del Novecento (2004), além de casos reportados em revistas como Journal of Architectural Conservation, Monuments Historiques, Arkos, Docomomo Journal e APT Bulletin.

\section{Por que conservar a arquitetura moderna?}

A arquitetura moderna foi fruto de uma era marcada pelo advento da ciência, da produção em massa, das novas democracias, da industrialização, do crescimento desmesurado das cidades, dos novos meios de transporte, de novas demandas e de novos tipos de edifícios. Após estabelecer seu programa e suas formas essenciais nos anos 1920, a arquitetura moderna foi transplantada para regiões que não eram urbanas e industriais e que estavam longe de um processo de reforma social. Ela teve de lidar com a diversidade: diversidade de programas, de lugares e de culturas. Seus aspectos universalizantes tiveram de dialogar com heranças históricas, práticas vernaculares de construção e continuidades clássicas. Essa diversidade é hoje entendida como uma importante herança cultural do século 20 (MAXWELL, 1998, p. xv). Como Jukka Jokilehto notou:

\footnotetext{
Modernidade não é um estilo, mas uma abordagem cultural que penetrou todas as regiões do mundo e é expressa em uma variedade de formas. É esta pluralidade de expressões que representa nossas culturas contemporâneas e que forma nosso patrimônio recente. (JOKILEHTO, 2003, p. 109).
}

Diante de uma definição tão feliz e clara de Jokilehto, a pergunta do título acima pode parecer ingênua e inócua, mas a conservação dessa arquitetura ainda não é uma unanimidade.

Nossas sociedades ainda não consolidaram a ideia de que a arquitetura moderna é um produto cultural e de que deve ser protegida para as futuras gerações. $O$ reconhecimento de um edifício como um bem cultural de uma comunidade leva certo tempo. Muitos edifícios modernos estão sob o risco de descaracterização ou demolição, mas muitos deles ainda não tiveram seus valores reconhecidos pela sociedade. Como Richard Longstreth advertiu: "Nós não podemos nos dar ao luxo 
de perder coisas que nós nem conhecemos bem ainda" (LONGSTRETH, 1995, p. i; 16). Portanto, uma ação rápida e eficaz é necessária para salvaguardar de forma preventiva edifícios que podem tornar-se bens culturais após uma avaliação mais cuidadosa.

A grande massa de nossas cidades é feita de edifícios modernos. Embora a maioria deles não possa ser considerada obra de arte, eles constituem um grande estoque construído que detém, e continuará detendo, um papel importante no dia a dia de nossas sociedades. A renovação do estoque construído ocorre de forma muito rápida e o que representa um alto custo social e ambiental para nossas sociedades. Encontrar um futuro para essa imensa massa de edifícios significa também dar um melhor futuro a nossas cidades. Na adaptação, reuso e renovação de edifícios de 30 ou 40 anos atrás, para que melhor sirvam às demandas de hoje, nós não podemos exigir criteriosas restaurações, como aquelas destinadas às obras-primas, mas não podemos permitir que se destruam suas qualidades e valores. Um equilíbrio deve ser atingido pelos conservadores, proprietários e usuários (ALLAN, 2007, p. 15).

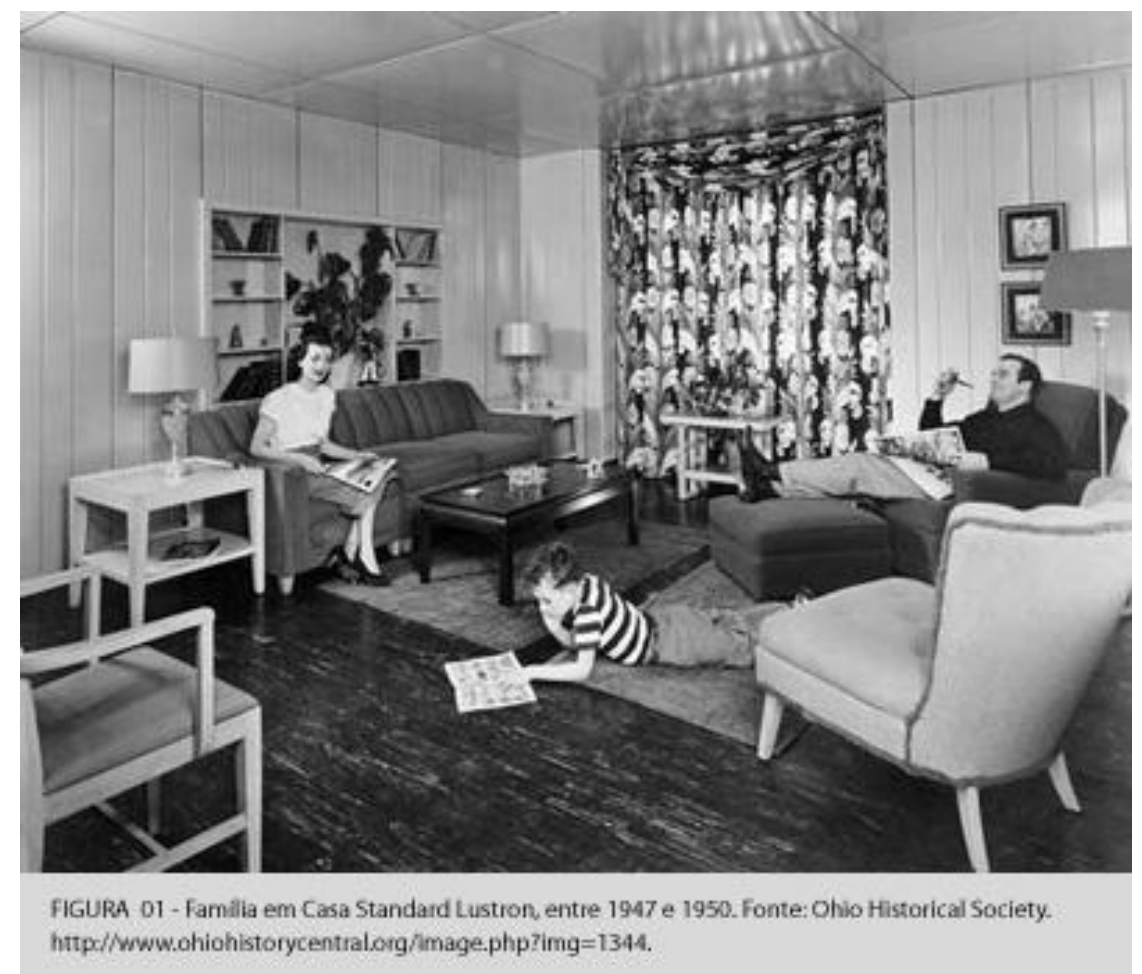




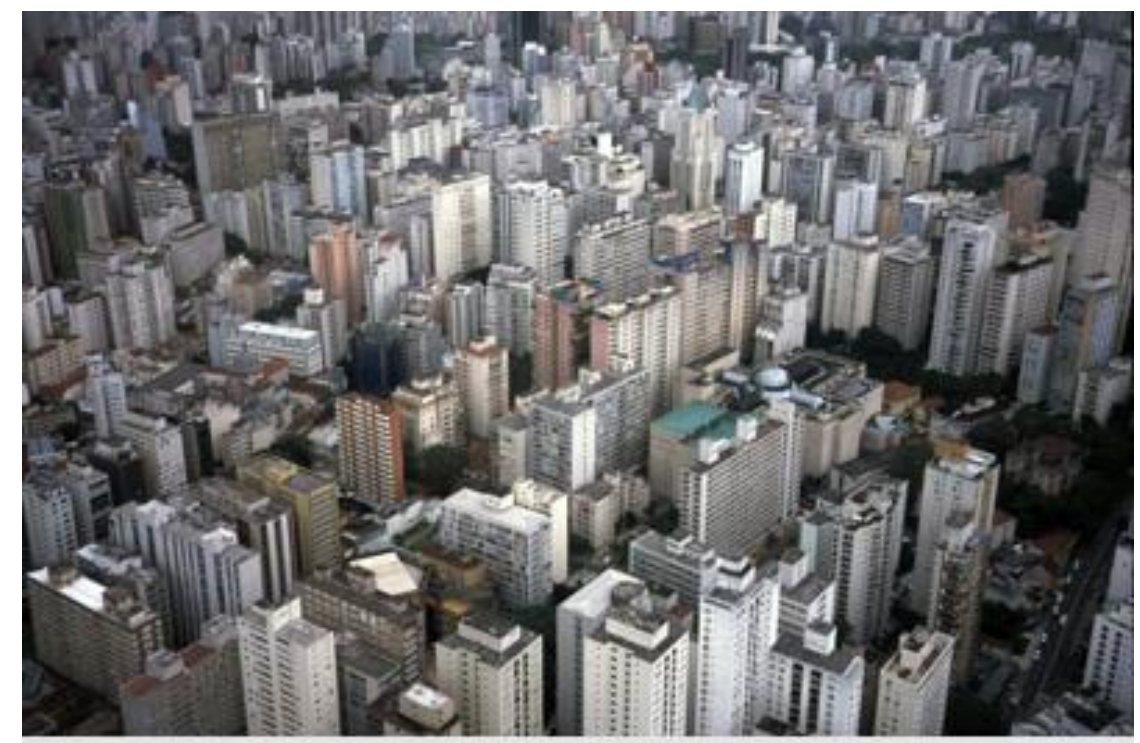

FIGURA 02-Sáo Paulo, Higiendpolis, Vista aérea. Fotografa: Paul Meurs.

Nós precisamos conhecer melhor nosso passado recente. Precisamos entender a forma de vida de nossos pais (ou mesmo a da nossa própria infância ou juventude), suas inovações técnicas, detalhes e desempenho físico de seus edifícios (JANHENKET, 1998, p. 14). Existem fotografias, plantas e outros documentos que constituem uma valiosa documentação para a conservação, além de importantes registros da história da construção. Muitos dos que projetaram ou construíram esses edifícios ainda estão vivos e podem contribuir enormemente para sua conservação, pois conhecem detalhes técnicos, especificações, problemas e mudanças feitas ao longo da construção. Esses edifícios da nossa modernidade podem nos ensinar a projetar melhor hoje.

Devemos conservar a arquitetura moderna também porque hoje temos uma relação mais madura com a herança do século 20. Acreditamos que superamos as polaridades que existiram entre os primeiros proponentes do movimento moderno e a crítica que sobreveio, particularmente entre os anos 1960 e 1970. Em todos os períodos históricos, a arquitetura teve de confrontar-se com novas demandas e condições, dando respostas criativas as essas. Na era moderna, os arquitetos foram obrigados a lidar com demandas mais complexas e lançaram mão de soluções inovadoras e ousadas, tanto em termos arquitetônicos como urbanísticos, as quais nem sempre foram bem sucedidas (JOKILEHTO, 2003, p. 109). No entanto, na perspectiva do início do século 21, percebemos que tanto essas soluções 
inovadoras como a crítica que se the seguiu formam a cultura arquitetônica e urbanística do século 20.

Por fim, é preciso admitir que conservar a arquitetura moderna não é contra a essência da própria modernidade. Parece uma ironia que estejamos agora tentando preservar uma arquitetura que era, em seu período de afirmação, contrária a qualquer forma de preservação (PRUDON, 1998, p. 89). Sant'Elia, o arquiteto do futurismo italiano, propôs a destruição dos edifícios do passado para se construir tudo a partir do zero, porque as "coisas durarão menos que nós, cada geração terá de fabricar sua própria cidade" (SANT’ELIA, 1999, p. 38). Mais recentemente, o arquiteto inglês Martin Pawley criticou o recente movimento pela preservação da arquitetura moderna com base nesse mesmo argumento (PAWLEY, 1993, p. 98 apud POWERS, 2001, p. 3).

Devemos superar de vez essa noção de que ela era contrária à preservação. De acordo com Hilde Heynen, um aspecto intrigante da modernidade é o conflito entre seu conteúdo programático (uma inabalável crença no progresso e no futuro e na emancipação das amarras do passado) e seu aspecto transitório (uma sensibilidade pelo efêmero, à fragmentação, à desconexão) (HEYNEN, 1998, p. 31). Tal conflito estava no cerne da clássica definição de modernidade de Marshall Berman:

Ser moderno é encontrar-se em um ambiente que nos promete aventura, poder, alegria, autotransformação e transformação das coisas em redor - mas, que ao mesmo tempo ameaça destruir tudo o que temos, tudo que sabemos, tudo que somos. (BERMAN, 1987, p.15).

Berman foi certamente influenciado por Walter Benjamin, que em uma de suas teses sobre o conceito de história, elabora esse aspecto da fragmentação trazida pelos tempos modernos por meio de um quadro de Paul Klee, Angelus Novus (BENJAMIN, 1985, p. 226). Nesse quadro, um anjo que fixa claramente um amontoado de ruínas causadas pelo progresso permite-nos entender a vulnerabilidade da arquitetura na modernidade. Apesar de seu caráter simbólico ela, paradoxalmente, não conseguiu permanecer muito tempo na paisagem da metrópole moderna: passagens, arcadas, halls de exposições foram destruídos pelo mesmo 
progresso que os criou (BENJAMIN, 1973, p. 13; 1999, p. 124). Possivelmente, o que Benjamin vislumbrou no final do século 19 é aquilo a que estamos assistindo em relação à arquitetura do século 20. O mesmo dilema do anjo da história de Benjamin guarda uma enorme semelhança com a forma que Berman vê o modernismo:

\footnotetext{
Se conseguir um dia se livrar dos desconfortáveis vínculos que o unem ao passado, o modernismo perderá todo seu peso e profundidade, e o turbilhão da vida moderna o alijará irreversivelmente. É apenas mantendo vivos estes laços que o ligam às modernidades do passado que o modernismo pode auxiliar os modernos do presente e do futuro a serem livres. (BERMAN, 1987, p. 346).
}

Assim, se é apenas entendendo suas continuidades com um passado mais distante que a arquitetura moderna adquirirá uma maior profundidade, é apenas conservando-a, que poderemos prever uma continuidade com o futuro. Dessa forma, entenderemos a arquitetura moderna como parte do desenvolvimento de nossa cultura, superaremos a noção de que ela foi contra a preservação e conseguiremos cumprir nosso papel perante as gerações futuras.

\section{Os desafios da conservação da arquitetura moderna}

Nos últimos quinze anos, assistimos muitos casos de intervenções e restaurações de edifícios modernos, algumas bem sucedidas e outras que comprometeram irreversivelmente o valor dos bens. Não acreditamos que a conservação da arquitetura moderna deva ser diferente da conservação de obras de um passado mais distante, nem que devamos criar toda uma nova teoria da conservação para lidar com ela. No entanto, não podemos deixar de reconhecer que sua conservação apresenta novos desafios que merecem uma reflexão mais cuidadosa. De acordo com Susan McDonald e Theodore Prudon, os desafios são:
1. Funcionalidade
2. Materiais
3. Sistemas infraestruturais
4. Falta de manutenção
5. A conservação de conjuntos habitacionais
6. Pátina 


\section{Reconhecimento e tombamento}

\subsection{Funcionalidade}

Para estar sempre em uso, um edifício necessita ser submetido a mudanças contínuas durante sua vida, caso contrário, pode se tornar inutilizável e, a longo prazo, uma ruína. Até o século 19, as transformações de programas edilícios eram lentas. Muitos edifícios nas áreas centrais de antigas cidades europeias foram continuamente modificados por séculos, e alguns mesmo por milênios. Após a Revolução Industrial, as mudanças tornaram-se muito mais rápidas devido às novas demandas espaciais e funcionais e às inovações tecnológicas. Mesmo quando um edifício mantém seu uso, a forma de levar esses usos a efeito pode sofrer grandes transformações. A forma como as pessoas usam os edifícios de escritórios hoje, por exemplo, é completamente diferente daquela de 20 anos atrás. Essa especialização crescente torna os edifícios modernos particularmente vulneráveis às transformações (JAN-HENKET, 1998, p. 17; PRUDON, 2008, p. 33). Quando um edifício adquire significância cultural, essa transformação, que deveria ser um fato natural, merece nossa atenção, ou seja, ela não deve ser uma simples reforma ou modernização, mas deve fazer parte de uma operação de conservação.

A atenção cuidadosa que os arquitetos modernos dedicaram aos aspectos funcionais na definição dos espaços dos edifícios provavelmente dificultou a introdução de novos usos. As atividades transformam-se com o tempo, mas um edifício é estático. Na era moderna, novas tipologias, como aeroportos e cinemas foram criadas mas, décadas depois, devido às crescentes complexidades de seus usos (no primeiro caso) ou às transformações que o mercado impõe (no segundo caso), tornaram-se obsoletas. O Aeroporto Dulles e o terminal da TWA no Aeroporto JFK em Nova York, ambos de Eero Saarinen são ótimos exemplos de formas que ficaram obsoletas imediatamente após a inauguração, devido ao enorme aumento do número de voos e às novas medidas de segurança. No entanto, como marcos da arquitetura do século 20 , foram preservadas, embora com um custo operacional alto. Enquanto que o Dulles foi significativamente ampliado, graças à flexibilidade demonstrada por sua estrutura em pórticos, O TWA foi desativado em 2001. Inúmeros planos foram discutidos, mas desde 2006, uma outra companhia aérea que ocupa o terminal vizinho está conduzindo a construção de um terminal maior 
que irá utilizar o edifício de Saarinem como portal de entrada (PRUDON, 2008, p. 31-32, p. 432-433).

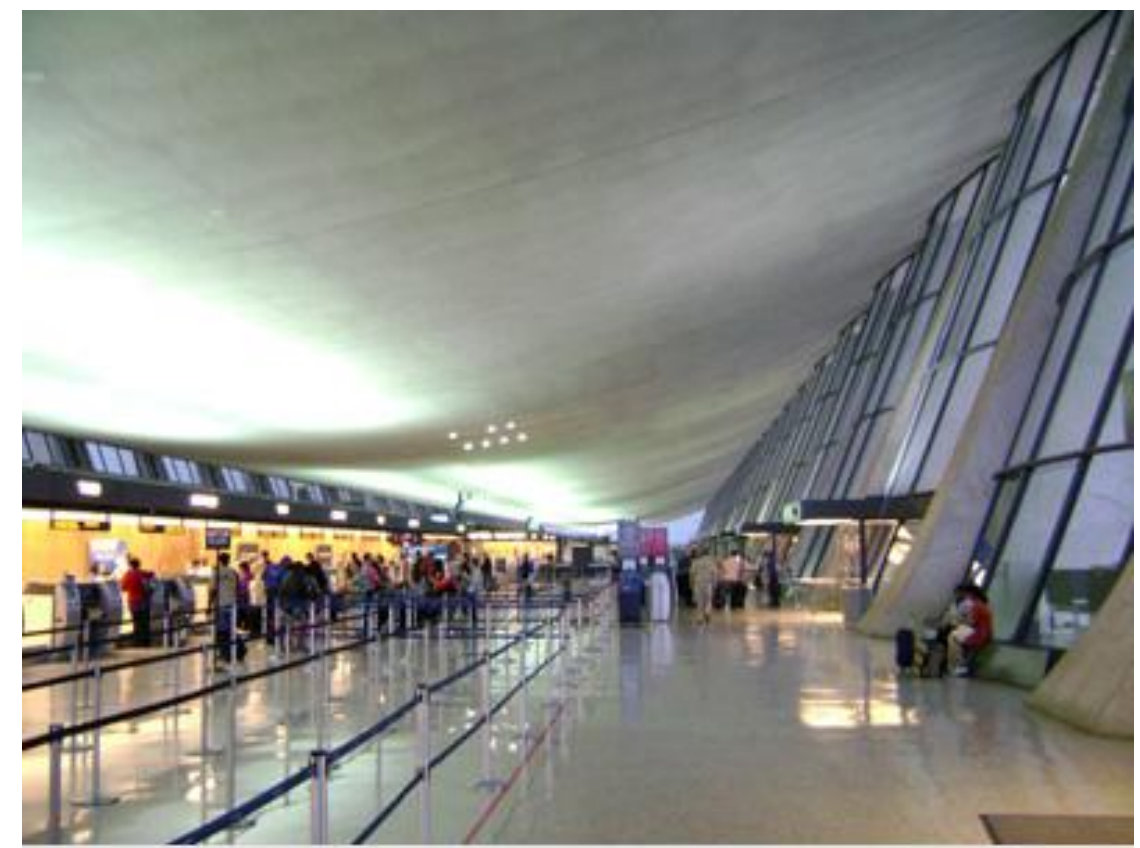

FIGURA 03 - Eero Saarinen, Dulles Airport, Chantilly, Virginia, 1958-62. Fotografia: Fernando Diniz Moreira.

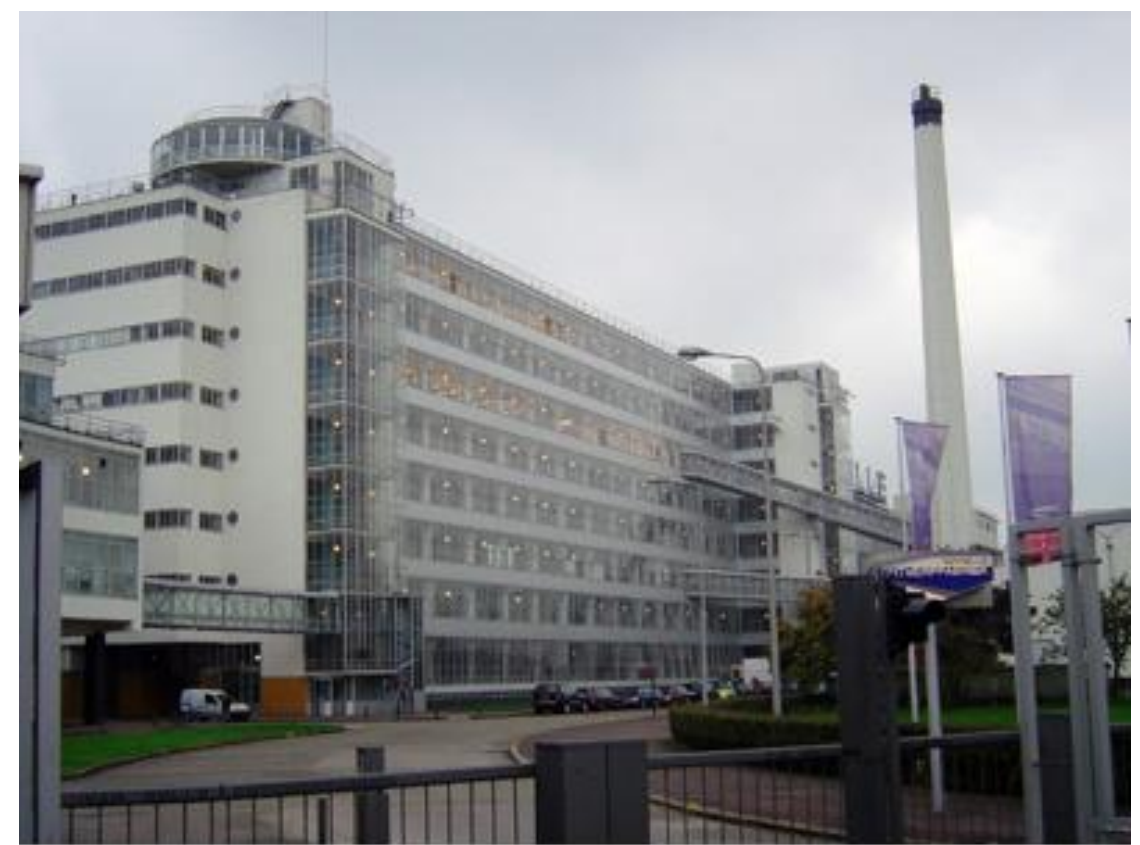

FIGURA 04 - Brinkmann \& Van der Vlugt, Van Nelle Factory, Rotterdam, 1927-29. Fotografia: Fernando Diniz Moreira.

Portanto, a funcionalidade de muitos arranjos espaciais modernos pode tornar mais difícil a inserção de novos usos. Como edifícios com grandes panos de vidro podem 
ser adaptados aos novos padrões espaciais? Como encontrar usos para fábricas ou para edifícios com usos bem específicos? A famosa fábrica Van Nelle, projetada em 1927 por Brinkmann \& Van der Vlugt em Rotterdam, foi adaptada com sucesso em um conjunto de escritórios na década de 1990 (PRUDON, 2008, p. 468-72). A mesma sorte não teve a fábrica de borracha Brynmawr, projetada em 1946 no País de Gales pelo grupo The Architect's Co-Op, que foi demolida em 2001, depois de fracassadas tentativas de encontrar-lhe um novo uso (SAINT, 1996, p. 25).

A obsolescência dos edifícios não é causada apenas pelas mudanças de uso ou pelas novas formas de levar a efeito este uso. Certos requisitos exigidos pela legislação atual em relação à performance dos edifícios tem efeitos desastrosos sobre estes. Como manter um edifício moderno comercial diante dos novos requisitos de acessibilidade e de vagas de estacionamento (que não existiam quando o edifício foi construído)? Como edifícios podem ser adaptados aos novos padrões de requisitos de isolamento térmico e de segurança, visto que foram projetados em uma era que a energia parecia inesgotável? Esse é um problema para os países escandinavos. Diante do novo contexto de redução do consumo de energia, os governos locais e a União Europeia subsidiam reparos que visam aumentar a eficiência energética, ou seja, novas camadas de isolamento térmico e novas janelas que reduzam a dissipação do calor interno. Assim, muitos edifícios modernos estão tendo seus painéis de concreto revestidos por camadas de isolamento térmico e suas janelas de ferro ou madeira substituídas por janelas novas de alumínio ou PVC, ações que comprometem a autenticidade dos mesmos (MOREIRA; NASLAVSKY, 2007).

Outra questão que se coloca é como conservar edifícios que foram pensados para um curto ou curtíssimo período de vida (MACDONALD, 2003, p. 4). A maioria dos pavilhões de exposição, como o famoso Pavilhão de Mies Van der Rohe em Barcelona, e o Pavilhão da Venezuela de Carlos Raúl Villanueva na Feira de Montreal de 1967, foram demolidos após os eventos para os quais foram construídos, sendo o primeiro reconstruído em 1986. O sanatório Zonnestraal em Hilversum, Holanda, foi projetado por Duiker e Bijvoet para durar apenas 30 anos, segundo com o qual se acreditava que a tuberculose estaria extinta na Europa. $O$ concreto foi feito de uma forma tão fluida que, cinquenta anos após a construção, 
sua estrutura estava totalmente comprometida, o que acarretou desafios para a conservação (DE JONGE, 1998, p. 149-158; PRUDON, 2008, p. 500-510).

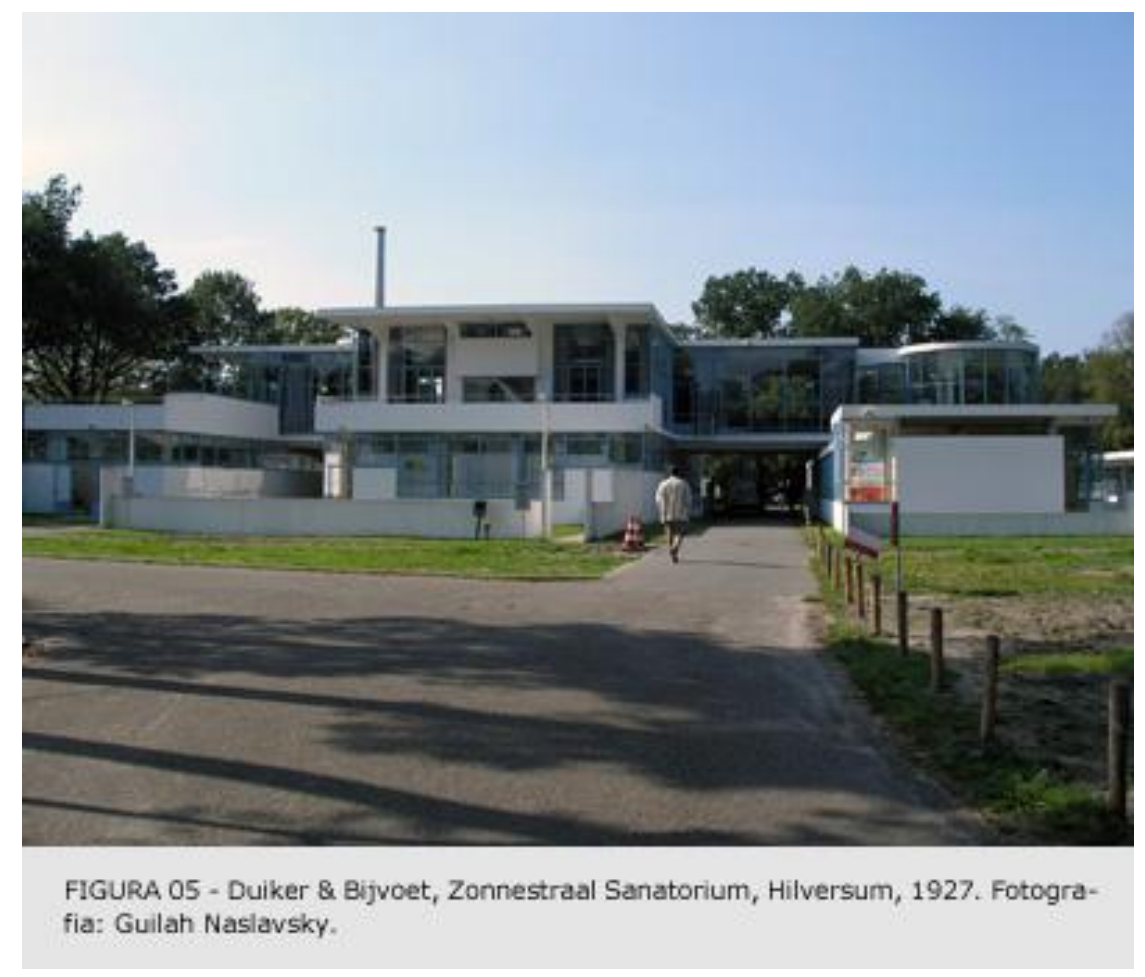

O argumento de que os edifícios modernos foram projetados para um curto espaço de tempo é válido apenas para um pequeno número de edifícios, como os acima mencionados, e não pode ser estendido a todos os edifícios modernos. A questão da transitoriedade deve ser entendida como parte da abordagem do arquiteto e deve ser levada em conta em uma operação de conservação (DE JONGE, 1995).

Segundo Theodore Prudon, a ênfase na funcionalidade era parte da filosofia e da estratégia do design (PRUDON, 2008, p. 89). Os edifícios modernos podem ser menos flexíveis que seus antecessores em acomodar mudanças, mas isso não pode ser uma desculpa plausível para deixar esses edifícios serem destruídos ou irremediavelmente transformados. Com inventividade e com atenção às teorias da conservação, eles podem ser adaptados a novas funções e reutilizados.

\subsection{Materiais}

A dimensão material dos edifícios modernos criou certas dificuldades para a sua conservação. Métodos e materiais tradicionais não foram abandonados, mas 
utilizados de novas maneiras ou em combinação com novos materiais. Modificar a forma como eles foram usados pode criar uma série de problemas difíceis de ser resolvidos. Por exemplo, a pedra, que foi usada por séculos como material de construção, foi utilizada em edifícios modernos como revestimento. Essa nova forma de usá-la criou alguns problemas, visto que as finas placas de pedra reagem como as peças metálicas usadas para conectá-las à construção, o que causa oxidação ou outras reações. Pedras foram transportadas para revestir fachadas em lugares distantes de sua origem, causando falhas quando expostas a outro clima. Esse problema ocorreu na fachada do Finlandia Hall de Alvar Aalto (1965-1975), no qual as placas de mármore carrara italiano se deformaram quando expostas ao inverno finlandês. Além disso, os suportes não foram adequadamente dispostos, abrindo fissuras nas placas. Esses problemas começaram a ser percebidos cinco anos após a inauguração e todo o mármore foi trocado em 1997 (MACDONALD, 2003, p. 7; PRUDON, 1998, p. 90).

Em segundo lugar, a falta de um entendimento do desempenho dos novos materiais no longo prazo, como o concreto. Como bem ressaltou Susan Macdonald, desenvolveu-se uma crença de que o concreto seria um material inabalável, eterno, que não necessitaria manutenção (MACDONALD, 2003, p. 6). Tal otimismo, infelizmente, não se concretizou. Quando o concreto é exposto à umidade, inicia-se um processo natural chamado de carbonatação, que ocorre a partir da reação entre o gás carbônico existente no ar e os compostos alcalinos presentes no concreto. Quando o concreto é poroso ou apresenta trincas e fissuras, ele permite a passagem de água, oxigênio e gás carbônico que vão deteriorando o próprio concreto até atingirem a armadura, que passa a sofrer corrosão. A penetração de cloretos também está colocando muitas estruturas de concreto em risco, pois quando estes cloretos atingem a armadura inicia-se o processo de corrosão que coloca em risco a estrutura por inteiro.

O uso do concreto exposto, muito comum em todo o mundo entre o pós-guerra e a década de 1970, contribuiu para esse processo de degradação. Em regiões tropicais, a umidade imprimiu manchas nas superfícies, fazendo com que proprietários e usuários as revestissem com cerâmicas ou pastilhas. Esse procedimento afetou tremendamente a autenticidade do material e a expressão 
original do edifício, que representava certas posições sociais e arquitetônicas características, que devem ser levadas em conta durante o processo de conservação.

A conservação de estruturas de concreto quase sempre altera a autenticidade do material e dá orgiem a questionamentos que desafiam a teoria da conservação. $\mathrm{A}$ Igreja de Notre Dame Du Raincy, projeto de Auguste Perret de 1923, teve de ter todos os seus elementos vazados e os blocos de concreto gradualmente substituídos, pois apresentavam várias fissuras e suas armações comprometidas. Conservou-se o projeto original de Perret, mas muito pouco do material original (MOUTON, 1998, p. 60-65; DONZET, 1985, p. 69-71). A piscina dos pinguins do zoológico de Londres, projetada por Berthold Lubetkin em 1930, famosa por suas ousadas rampas que se entrecruzavam no ar, apresentava sérios problemas em suas estruturas. A Avanti Architects, com a participação do próprio Lubetkin, empreendeu uma restauração do edifício no final dos anos 1980, na qual foi feita uma opção clara pela restauração do design original em detrimento da fábrica do edifício que estava irremediavelmente comprometida (ALLAN, 1996, p. 126). Por fim, o já mencionado sanatório de Zonnestraal foi outro caso intrigante. Como já foi visto, talvez devido ao fato de o edifício ter sido construído para durar apenas 30 anos. período no qual a tuberculose estaria extinta, o concreto foi feito tão fluido e as lajes tão finas que a estrutura estava virtualmente condenada décadas depois. A única solução para preservar o edifício, um marco da arquitetura dos anos 1920, foi refazer grande parte da estrutura (DE JONGE, 1998, p. 149-148; PRUDON 2008, p. 500-510). Esses casos acima mostram intervenções radicais, que seriam condenadas pelas convenções da conservação, mas tiveram de ser feitas para salvaguardar esses edifícios, exemplificando os desafios que a conservação desta arquitetura traz para a arquitetura moderna. 


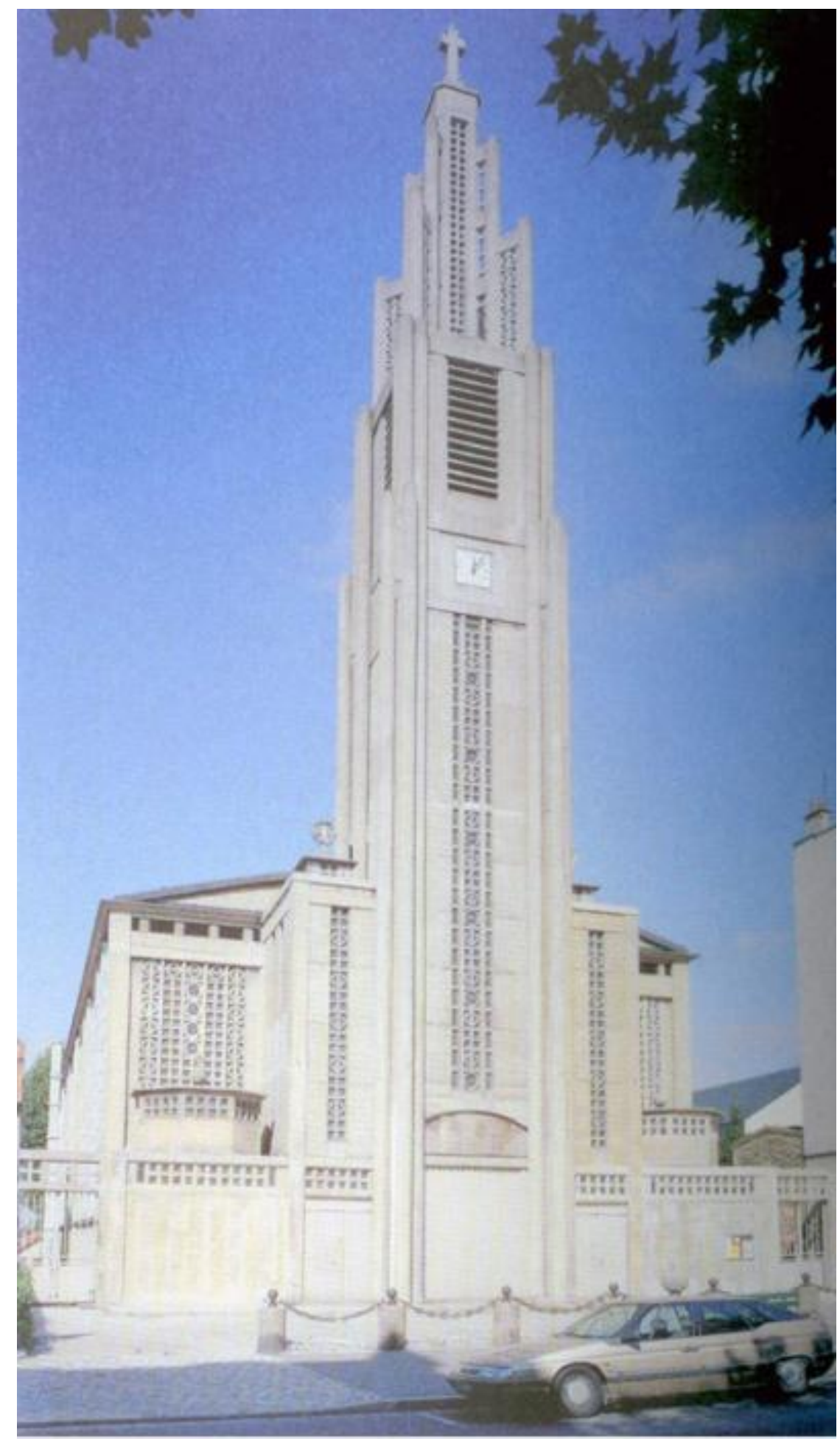

FIGURA 06 - Auguste Perret, Notre Dame du Raincy, 1922-23. Fonte: Karla Britton. Auguste Perret. London: Phaidon, 2001, p. 78. Fotografia: Karla Britton. 


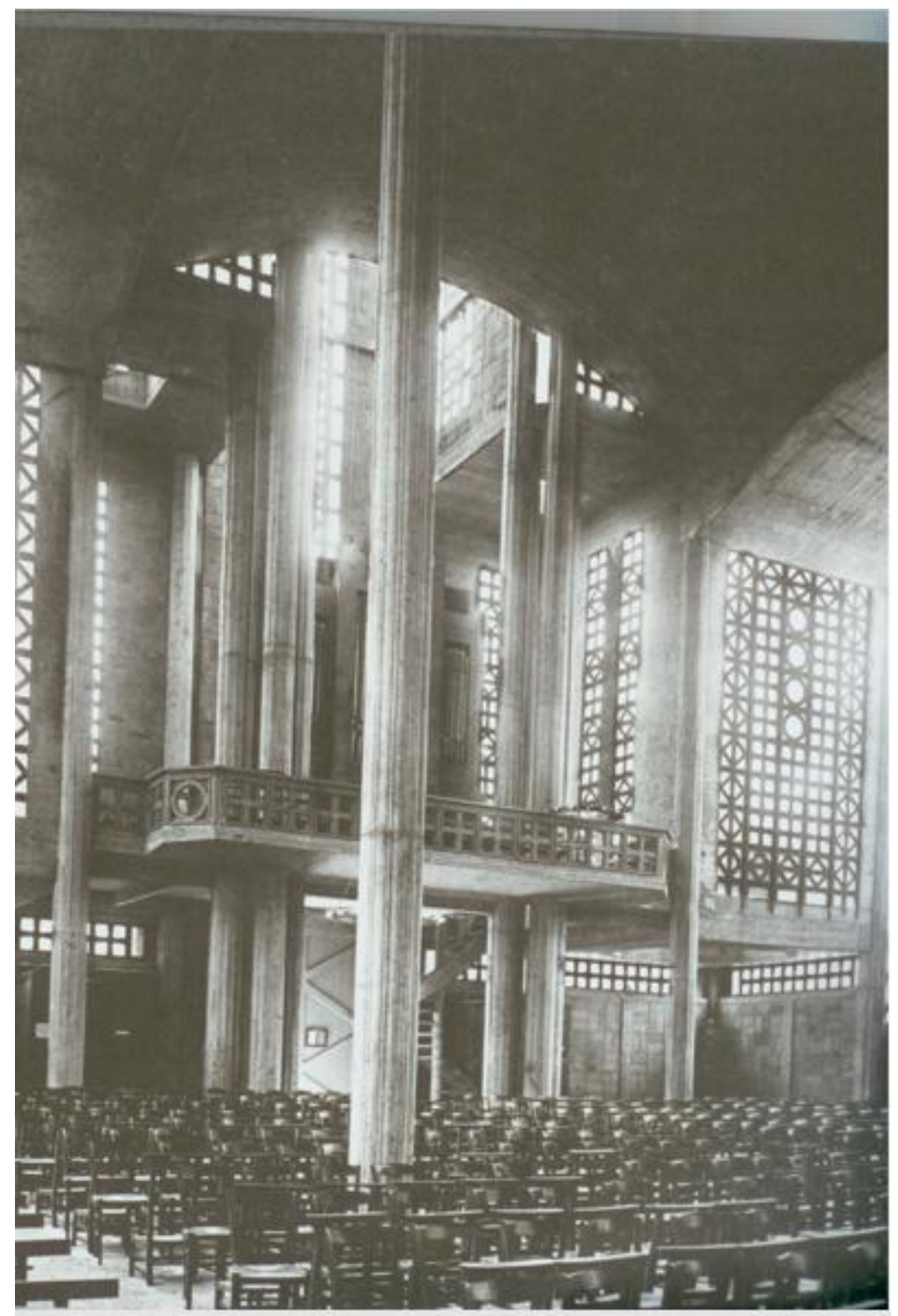

FIGURA 07 - Auguste Perret, Notre Dame du Raincy, 1923, interior. Fonte: Karla Britton. Auguste Perret. London: Phaidon, 2001, p. 76 . Coleçāo Institute Français d'Architecture. 


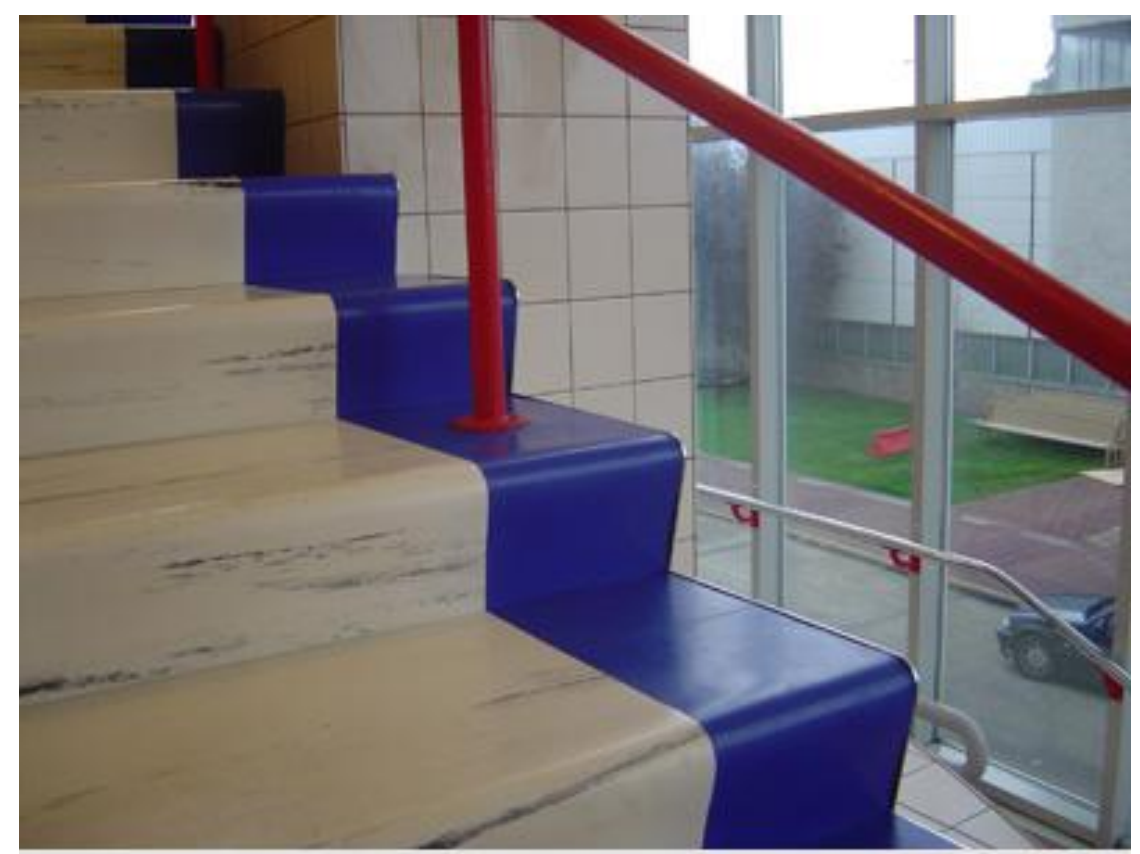

FIGURA 08 - Brinkmann \& Van der Vlugt, Van Nelle Factory, Rotterdam, 1927-29, escada. Fotografia: Fernando Diniz Moreira.

Além do concreto, o século 20 assistiu a uma proliferação de novos materiais que entraram em uso sem um conhecimento completo de suas qualidades e propriedades. Novos materiais, como linóleo, plywood, fibra de vidro e outros acabamentos plásticos, metálicos ou vitrificados colocam enormes desafios para os conservadores da arquitetura (PRUDON, 2008, p. 135-141). As técnicas apropriadas para conservação de semelhantes materiais ainda não foram completamente desenvolvidas.

Em terceiro lugar, devem-se mencionar as falhas na construção devido à mão de obra pouco qualificada, às restrições orçamentárias e ao pouco conhecimento sobre o comportamento e o envelhecimento dos materiais. A igreja de São Francisco da Pampulha (1943), de Oscar Niemeyer, é um ótimo exemplo. O projeto original previa três juntas de dilatação na abóbada principal de concreto, mas só duas foram construídas, e ainda assim fora das especificações. O resultado é que as pastilhas começaram a se soltar após alguns anos do término da construção, um problema que reapareceu constantemente nos anos seguintes, até terem sido sanadas na última restauração, em 2004 (PROJETOS..., 2006, p. 20-23). 

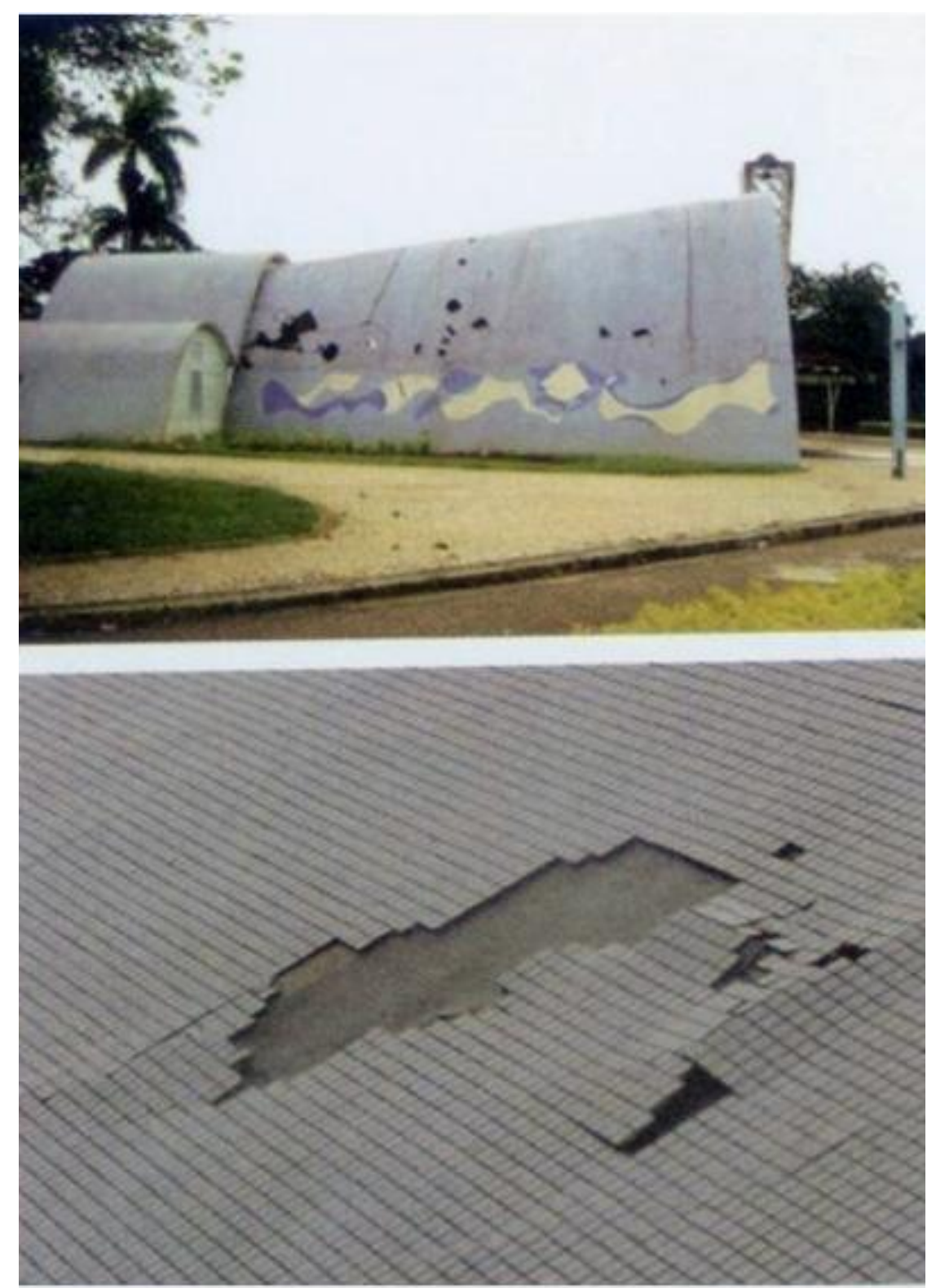

FIGURA 09 - Oscar Niemeyer, Igreja de São Francisco, Pampulha, em 2004. Fonte: PROJETOS e obras de recuperação da Igreja da Pampulha. In: Mariangela Castro; Silvia Finguerut (org.). Igreja da Pampulha: restauro e reflexōes. Rio de Janeiro: Fundação Roberto Marinho, 2006, p. 22.

Em quarto lugar, encontram-se problemas gerados pela maneira como os edifícios modernos foram detalhados. Muitas vezes, o abandono de detalhes tradicionais em prol de detalhes inovadores que procuravam expressar a novidade daquela arquitetura resultou em falhas técnicas que causaram problemas de conservação (ALLAN, 2007, p. 17; MACDONALD, 1996a, p. 44). Deve-se ressaltar também que esses detalhes inovadores falharam ao colocar juntos materiais que não reagiram entre si. O conjunto Farum Midpunkt (1968-1972), projetado por Windinge \& Moller nos arredores de Copenhagen, teve suas superfícies de concreto marcadas pela 
corrosão das placas de aço cortém, um problema similar ao que ocorreu com o Jonas Salk Institute (1966-68) de Louis Kahn, próximo de San Diego.

Tais problemas também estão relacionados com o fato de muitas inovações estarem à frente do que a indústria da construção da época poderia oferecer. Por exemplo, os telhados planos foram sendo colocados em prática nos anos 1920, quando ainda não tinham sido desenvolvidos produtos isolantes adequados. Da mesma forma, fachadas de vidro foram construídas quando a técnica do sistema curtain-wall e do ar condicionado ainda não estavam disponíveis, como os problemas da Cité Du Refuge de Le Corbusier mostraram. Entretanto, é importante notar que esses "erros" são parte do risco de se propor algo novo e também possuem um valor histórico por si próprios, como registro dos percalços da história da construção.

Em quinto lugar, foi identificado o uso de materiais fabricados em série. Fachadas inteiras foram revestidas por azulejos ou pastilhas cerâmicas que, como são feitas industrialmente, tiveram sua produção interrompida alguns anos, ou mesmo meses, depois de utilizadas. Hoje não há como substituí-las, exceto pela feitura artesanal delas, o que acarreta um custo considerável (MACDONALD, 2003, p. 6; 1996a, p. 45). Esse é um problema que afeta tremendamente a arquitetura latino-americana. Muitos edifícios modernos residenciais construídos entre os anos 1950 e 1980 estão sendo revestidos novamente com outros tipos de cerâmicas, o que elimina detalhes e composições originais.

Por fim, deve-se ressaltar $\underline{0}$ uso de materiais que não eram conhecidos como prejudiciais à saúde, como o cimento amianto (asbestos), muito utilizado nos anos 1960 e 1970. Nos países europeus, as novas normas exigem que materiais desse tipo sejam retirados dos edifícios, apesar de estarem em boas condições. A retirada desse material irá afetar a autenticidade das superfícies e, em alguns casos, pode representar mesmo a demolição do edifício, como o conjunto Faellestgnestuen (1963-1968), de Amfred \& Moller-Jensen, em Albertslund, nos arredores de Copenhague, todo feito em placas de cimento amianto. Não há suficiente experiência técnica acumulada para lidar com toda a diversidade de materiais e técnicas da arquitetura do século 20. Além disso, como Macdonald alerta, o objetivo não é apenas encontrar uma técnica de reparo adequada, mas reconciliá-la com os 
objetivos e as teorias da conservação (MACDONALD, 2003, p. 8, 1996a, p. 53; PRUDON, 2008, p. 178). A estratégia de um processo de conservação em tais edifícios não pode ser apenas "consertar" o que deu "errado" ou envelheceu precocemente. A intervenção do material deve respeitar sua autenticidade. No entanto, não podemos superestimar o valor dos materiais, porque, como já foi notado por vários autores, os materiais por si só não definem a essência dessa arquitetura, mas a forma como eles foram usados e o espaço que eles criaram. Isso não é uma permissão para que sejam consideradas as diferentes intervenções que ele sofreu para se voltar a uma condição imaculada e ideal, mas para alertar que o conceito de autenticidade deve ser ampliado para incluir espaço e intenção projetual (ALLAN, 1996, p. 126; SAINT, 1996, p. 20-22; DE JONGE, 1998, p. 155).

\subsection{Sistemas infraestruturais}

Os sistemas infraestruturais (aquecimento, resfriamento, água, eletricidade, redes de comunicação) assistiram a um enorme avanço nestas últimas décadas e são cada vez mais importantes no edifício contemporâneo. Muitas vezes, essas infraestruturas precisam ser substituídas para que o edifício possa continuar a ser utilizado. As partes metálicas sofrem erosão e corrosão. Em linhas gerais, esses sistemas são trocados por inteiro e raramente conservados. Tal fato acarreta uma série de problemas para a conservação de um edifício que possui uma vida útil mais longa que a dos seus sistemas. O prazo de vida de um sistema desses gira em torno de 30 anos. Então, um edifício com cerca de 60 anos teria seus sistemas trocados pelo menos uma vez. Se esse edifício adquiriu significância para determinada sociedade, um problema surge, pois o edifício precisará da renovação de tais sistemas para se manter em uso (e, consequentemente, bem conservado), e a introdução dos sistemas pode alterar características significativas do edifício (PARKES, 2001, p. 43). Devemos aceitar a necessidade de mudança, mas faz-se necessário um cuidadoso trabalho de adequação dessas novas estruturas. Os sistemas antigos representam um testemunho importante de nossa forma de morar no passado e não devem ser descartados, mas, sempre que possível, preservados ao lado dos novos como um registro. 


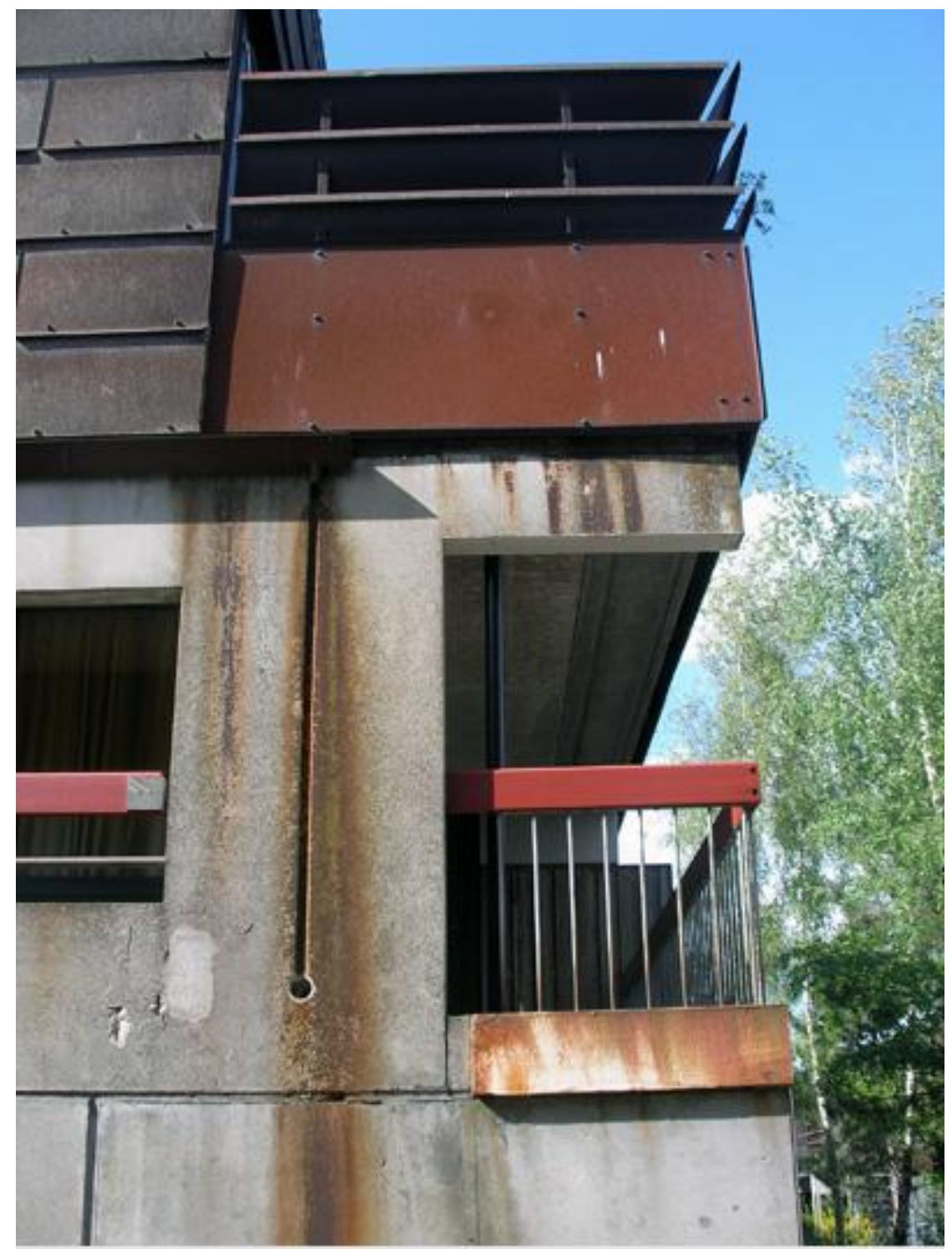

FIGURA 10 - Windinge \& Moller, Farum Midpunkt, Copenhague, 1968-72, detalhe. Fotografia: Fernando Diniz Moreira.

\subsection{A falta de manutenção}

A concepção de que os edifícios modernos não precisavam de manutenção foi outro elemento que contribuiu negativamente para a sua conservação. $O$ discurso arquitetônico modernista, com a sua insistência na excelência dos novos materiais e técnicas como alumínio, concreto armado e aço inoxidável gerou a crença de que esses materiais e técnicas durariam eternamente, o que afetou diretamente as atividades de manutenção (MACDONALD, 2003, p. 9). Alguns edifícios modernos trazem novos problemas para a manutenção, como é o caso dos edifícios altos. 
A manutenção preventiva de longo prazo é vista hoje como a melhor estratégia para todos os bens patrimoniais, inclusive os modernos. A prática ainda comum na América Latina é a de se restaurar um edifício apenas quando esse atinge níveis críticos de deterioração, o que faz com que os edifícios venham a sofrer restaurações a cada vinte ou trinta anos, levando a uma profunda alteração dos mesmos. É necessário criar sistemas de inspeção e manutenção periódica, que venham substituir os trabalhos de restauro, e um sistema de gestão visando à conservação e sustentabilidade do bem no longo prazo.

\subsection{Pátina}

Na teoria da conservação, a pátina de um lugar ou edifício é um sinal da passagem do tempo, o que muitas vezes enriquece o significado dos edifícios. No entanto, a pátina em um edifício moderno é entendida como sujeira ou degradação, e não como um sinal do envelhecimento natural do edifício (LEATHERBARROW; MOSTAFAVI, 1997, p. 16-17).

Parece que os edifícios modernos envelheceram de forma pouco elegante e a pátina não parece apropriada à sua imagem. As publicações de época que apresentavam materiais e superfícies brilhantes contribuíram para essa convicção de que os edifícios modernos deveriam continuar sempre inexoravelmente novos e dificultaram nosso entendimento da pátina no edifício moderno (MCDONALD, 2003, p. 10; PRUDON, 2008, p. 42-44). Fotografias da Villa Savoye em um estado decrépito, publicadas nos anos 1960, eram desconcertantes diante das imagens da casa publicadas após sua inauguração. Elas foram utilizadas tanto para criticar a arquitetura moderna como para sensibilizar as autoridades francesas para preservarem o edifício. A não aceitação da pátina levou muitas vezes à troca de materiais de revestimento em vez de sua recuperação e manutenção, afetando assim a autenticidade do edifício. 


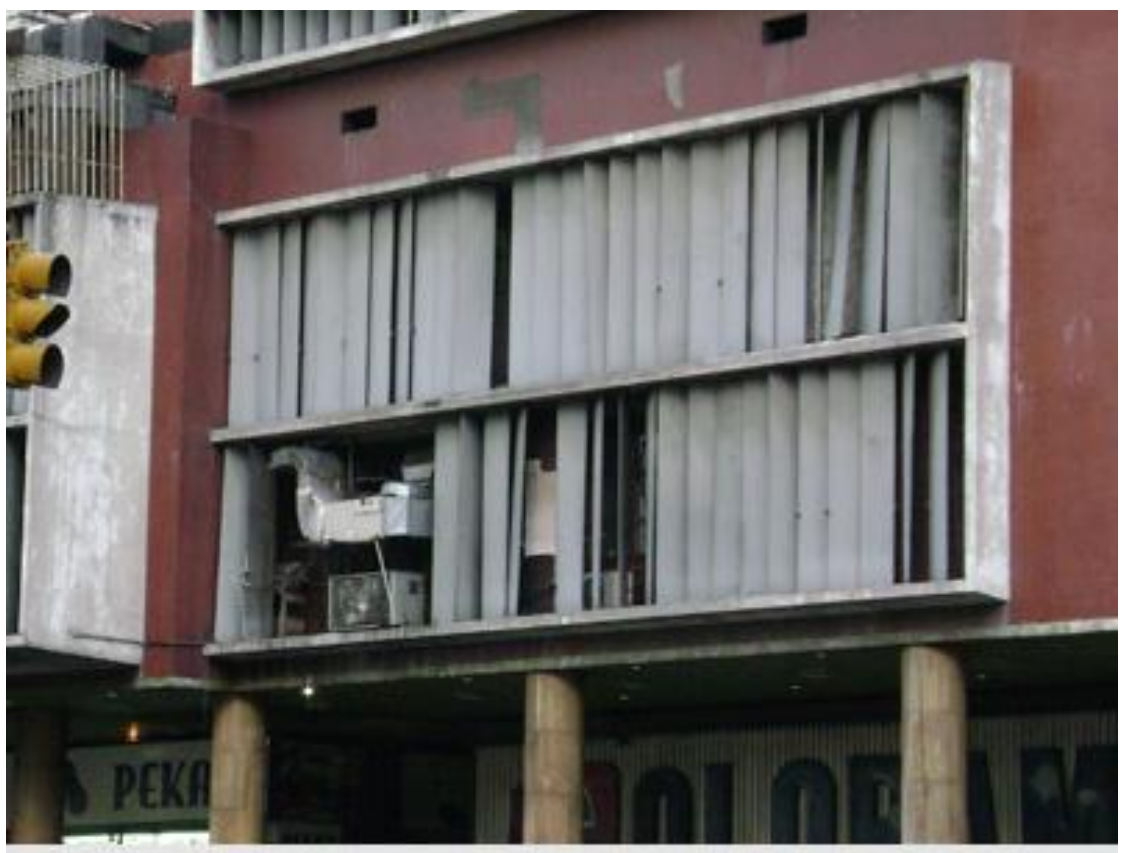

FIGURA 11 - Cipriano Dominguéz, Centro Simón Bolivar, Caracas, 1949-1957. Fotografia: Fernando Diniz Moreira.

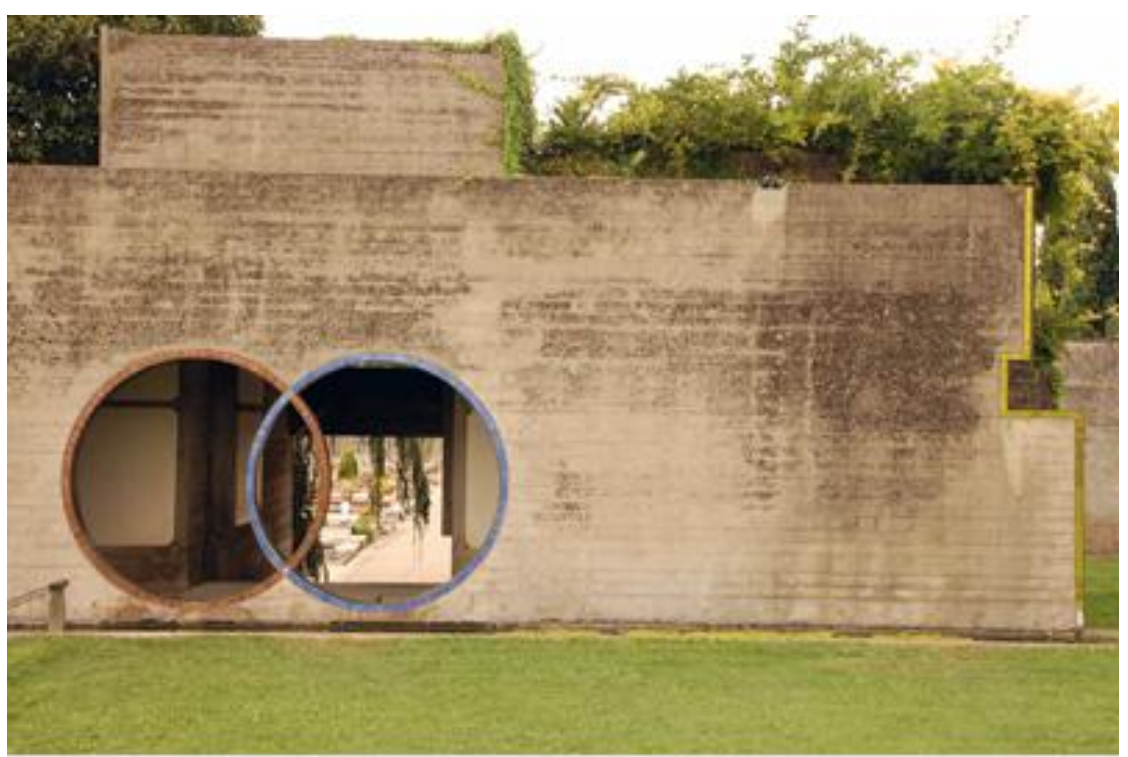

FIGURA 12 - Carlo Scarpa, Brion Cemetery, San Vito D'Altivole, Itália, 1968-74 pórtico. Fotografia: Diogo Barretto. 


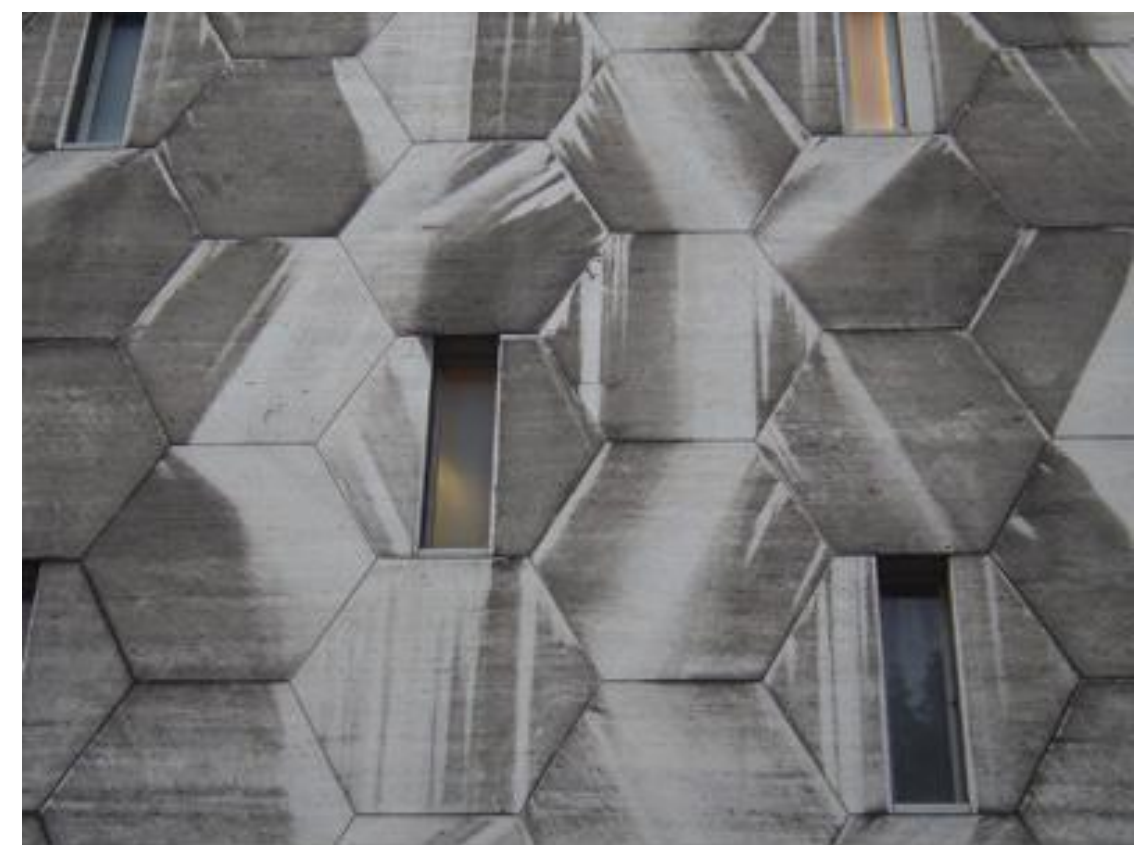

FIGURA 13 - Marcel Breuer, De Bijenkof Store, Rotterdam, 1955-57, detalhe da fachada Fotografia: Fernando Moreira.

Imagem e aparência desempenham um importante papel na arquitetura moderna, mas é preciso aceitar a pátina como algo natural a um edifício moderno. Às vezes, a pátina enriquece o significado dos edifícios, como é o caso do Cemitério Brion (1969-1978) de Carlo Scarpa, um arquiteto que se antecipava ao calcular o efeito da passagem do tempo em seus edifícios. A pátina, mesmo inesperada, também pode enriquecer um edifício moderno. As manchas que surgiram nas placas de mármore que revestem as fachadas da loja de departamentos De Bijenkof (1955-57), projetadas por Marcel Breuer em Rotterdam, conferiram uma inesperada beleza e terminaram sendo aceitas por todos (LEATHERBARROW; MOSTAFAVI, 1997, p. $98,41)$.

\subsection{Conjuntos habitacionais e o espaço entre os edifícios}

Grandes conjuntos habitacionais marcaram a paisagem de inúmeras cidades europeias e latino-americanas nas décadas do pós-guerra. Após alguns anos, eles revelaram uma dificuldade de adaptação às transformações sociais, como o envelhecimento, o enriquecimento ou o empobrecimento de sua população-alvo. Hoje, a maioria desses conjuntos apresenta inúmeros problemas de conservação: intempéries climáticas atacaram revestimentos, espaços comuns degradaram-se, estruturas de concreto ficaram comprometidas pela corrosão das ferragens e pela 
carbonatação. Muitas vezes, o rápido envelhecimento pode ser atribuído à má qualidade da construção e dos materiais empregados, devido às pressões para se construir com rapidez e quantidade, e à falta de uma política contínua de preservação dos espaços públicos.

O conjunto Pedregulho (1948-1960) no Rio de Janeiro, obra-prima de Afonso Eduardo Reidy, sofreu um processo de degradação violento devido à falta de uma política de manutenção e ao empobrecimento das áreas ao redor do conjunto (o que favoreceu a substituição da população original). Um dos mais extensivos programas habitacionais públicos de todo o mundo, o megaconjunto 23 de Enero, projetado por Carlos Raúl Villanueva, era composto por quase 60 torres espalhadas por áreas verdes ao redor de Caracas. A queda do ditador Pérez Giménez, e a convulsão política que se seguiu acarretaram a invasão de todas as torres e áreas públicas por uma população de baixo poder aquisitivo. Esses dois conjuntos apresentam problemas extremos de conservação e nenhuma alternativa no curto ou médio prazo aparece no horizonte.

Mesmo muito longe das pressões sociais da América Latina, também encontramos problemas de conservação. Nos arredores de Gotenburgo, o enorme conjunto de Gårdsten, um dos maiores símbolos do Welfare State sueco dos anos 1960, passava, já na década de 1980, por sérios problemas de conservação e continha inúmeros apartamentos abandonados. Tal situação mudou quando o conjunto passou a ser gerido por uma companhia privada, que iniciou um drástico processo de requalificação para recolocá-lo no mercado de aluguel. Para atrair novos moradores, foram feitas intervenções mais radicais, como a substituição de fachadas inteiras, cortes nos longos blocos de apartamentos e a criação de novas entradas. Nas cercanias de Helsinki, Pihlajamaki, o primeiro conjunto finlandês totalmente feito de elementos pré-fabricados, também apresentava problemas de conservação, sobretudo nos seus painéis de concreto. Apesar do esforço por manter a unidade do conjunto, foram introduzidos novos elementos, como elevadores e camadas de isolamento térmico, os quais interferiram na manutenção de sua autenticidade (MOREIRA; NASLAVSKY, 2007). 


\section{From grey concrete blocks..}
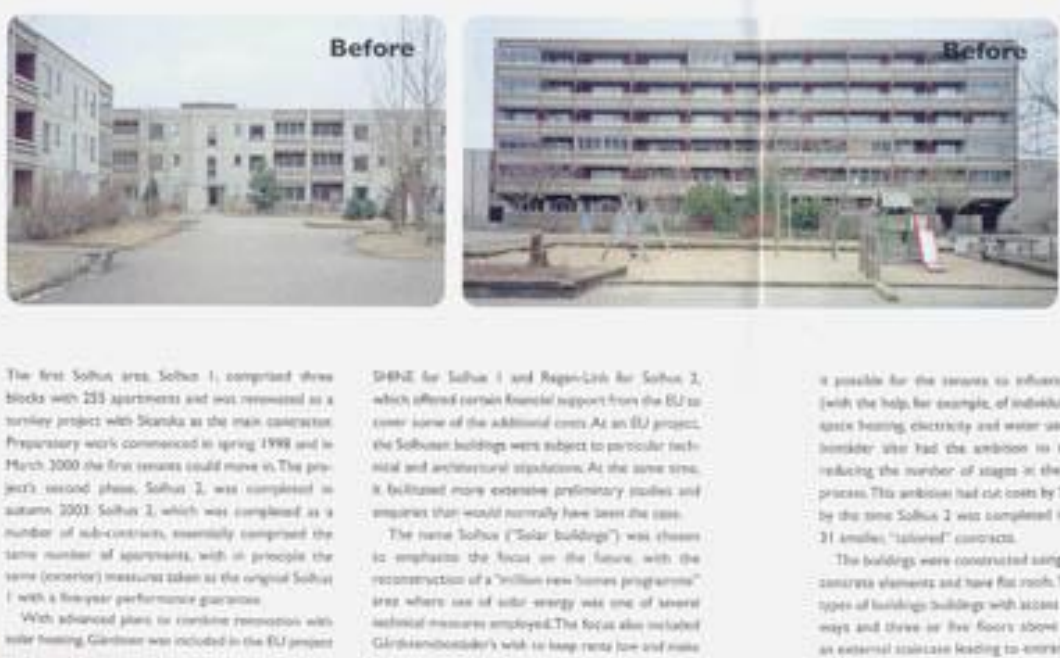

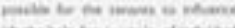

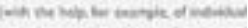

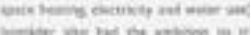

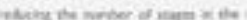

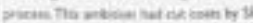

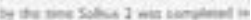

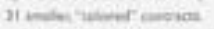

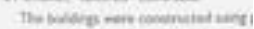

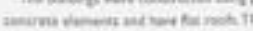

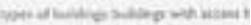

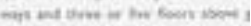

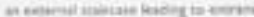

\section{...to open, bright "Solar buildings"}

The bakony access buldings were fitted with roofintegrated solar collectors which via accumularor tanks in the cellar, pre-hear hot waver in the block The balconies in the balcony access buildings were slazed to prosect the bades, reduce heat loss and improve the bakconiex. During spring and sutumn the von shining on the bakonies pre-hess the ven. thation air for the apartments. The open ground foors of the taicong xccess buldings at Sohnus 1 have been replated by sreenhounes for the tenants and new, bright bundry rooms and rooms directy aspacene to the greenhouses. which can be used by the tonants. In addition, compost machines translorm bousehold wivte into voll, which can then be uned in the greenhouses
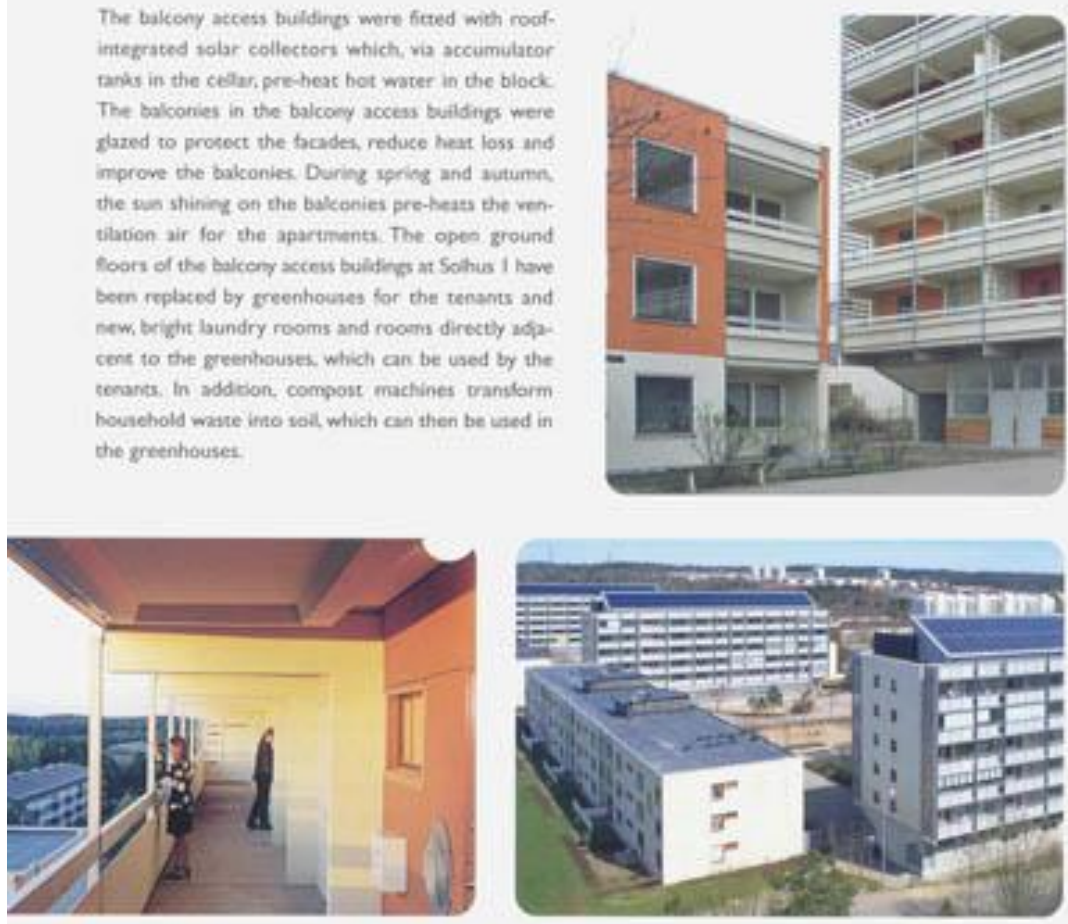

FIGURA 14 - Gårdsten. Antes e depois da intervençāo. Fonte: Frantidem. Gărdstensbostader. Gothenburg, 2003. 


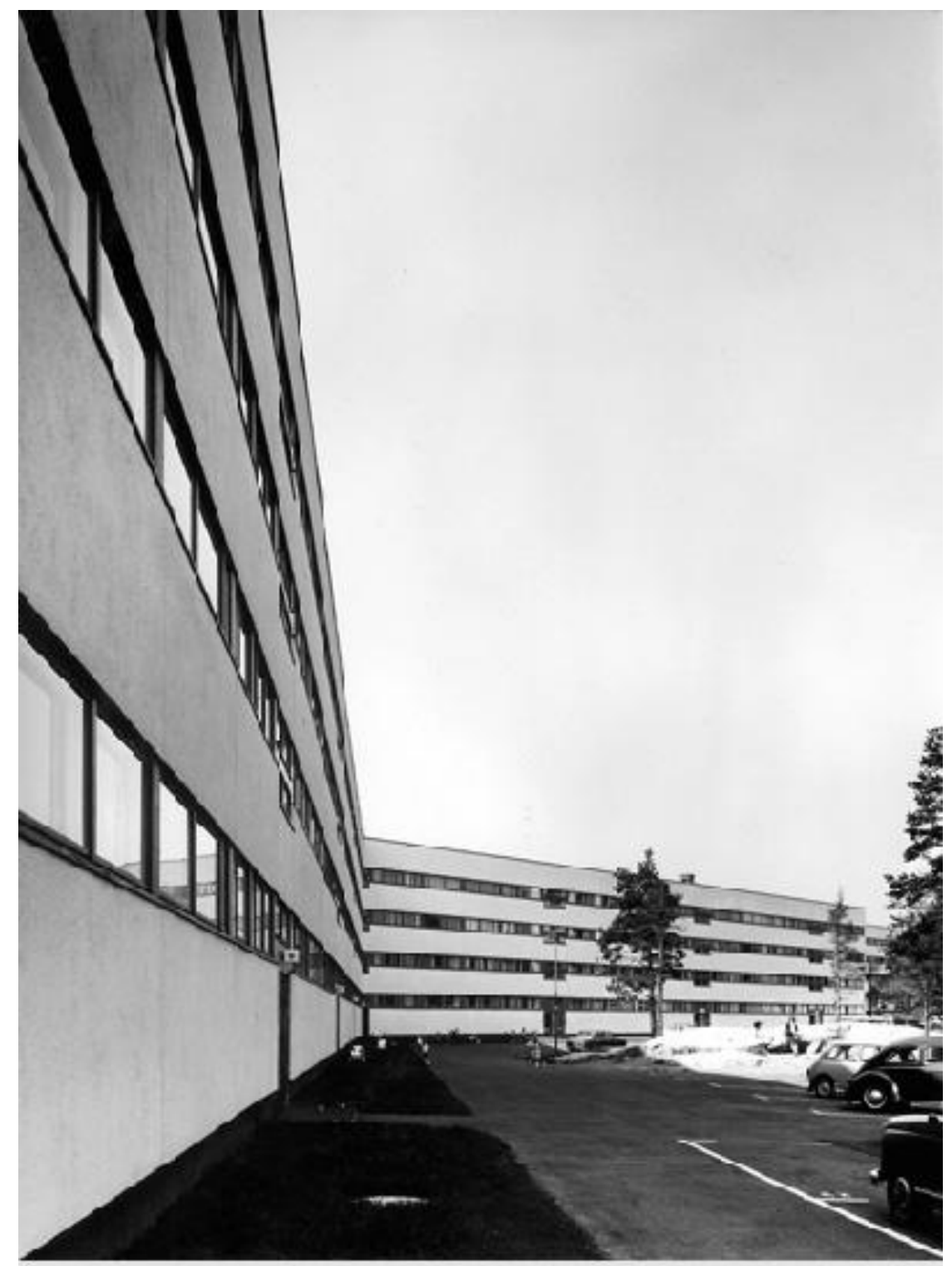

FIGURA 15 - Lauri Silvenoinen, Pihlajamaki, 1963-64, blocos originais. Fonte: Arkkitehti/ Arkitekten 10-11, 1964. 


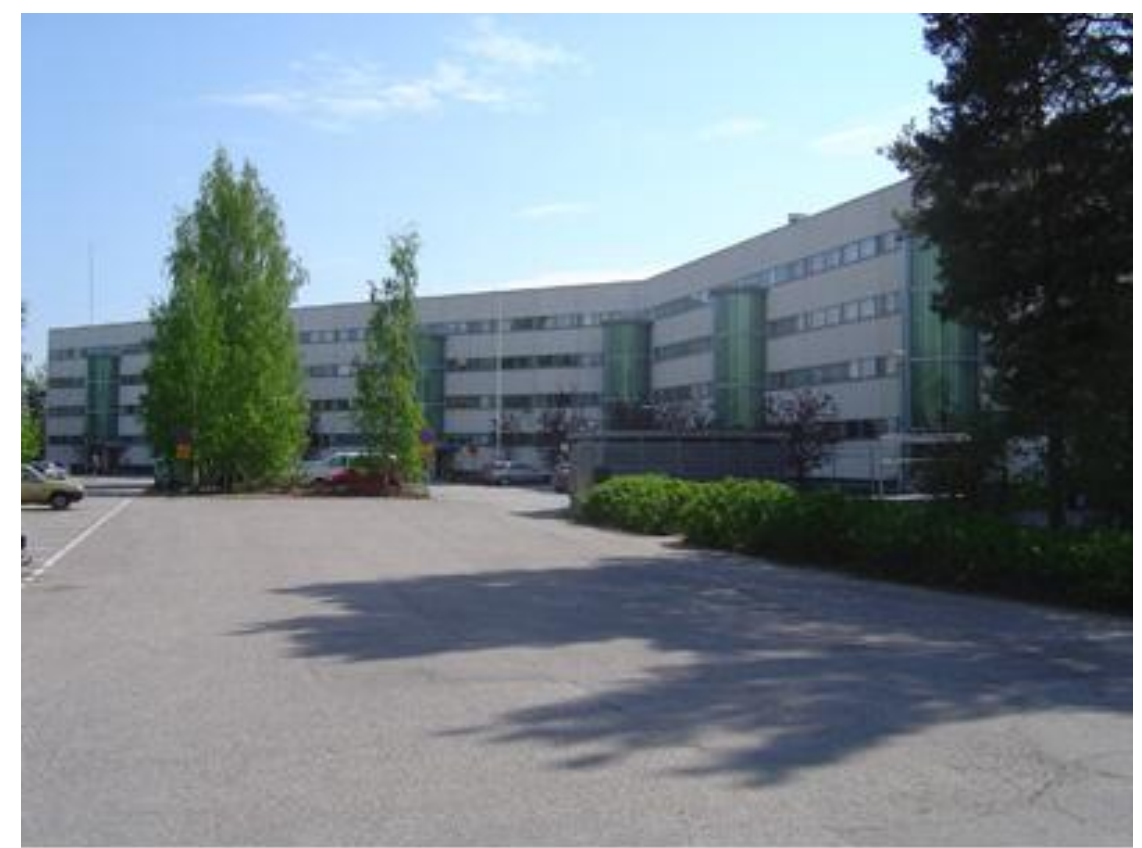

FIGURA 16 - Lauri Silvenoinen, Pihlajamaki, 1963-64, blocos com caixas-deescada adicionadas. Fotografia: Fernando Diniz Moreira.

Essas intervenções escandinavas suscitam uma série de questionamentos que podem ser generalizados para outros conjuntos: Como atender às novas demandas sociais, tecnológicas e energéticas sem alterar a integridade e a unidade estética desses conjuntos? Até que ponto são admissíveis mudanças sem alterar sua autenticidade? Como adaptar as disposições espaciais para as novas demandas? Quais os parâmetros mínimos a serem observados para a conservação? Qual o valor histórico e cultural desses conjuntos? Na conservação desses conjuntos também deve ser levado em consideração um fator peculiar, que é a comunidade residente. Embora essas comunidades geralmente não possuam uma percepção dos valores desses edifícios e espaços públicos, é essencial envolvê-las no processo de conservação.

\subsection{Reconhecimento e tombamento}

O reconhecimento e o tombamento de edifícios modernos ainda não é uma prática corrente, mesmo em países com uma forte tradição de arquitetura moderna como o Brasil, a Finlândia e os Estados Unidos. Ela ainda não atingiu o mesmo nível de aceitação que as arquiteturas de períodos anteriores. Particularmente nos Estados Unidos, uma crítica de viés populista nos anos 1960, que considerava esta arquitetura fria, indiferente á escala e desprovida de apelo popular, parece ter 
contribuído para o desinteresse da população em geral por essa arquitetura (PRUDON, 2008, p. 27-29).

Enquanto marcos do modernismo receberam uma atenção pioneira, inúmeros exemplares modernos aguardam reconhecimento. Após 30 e 40 anos de sua construção, um edifício entra em seu primeiro ciclo de reformas. Trata-se de um momento muito delicado, pois o edifício ainda não está registrado ou reconhecido como um bem, e essas reformas, por mais simples que sejam, podem eliminar importantes características do edifício. O reconhecimento e o tombamento da arquitetura moderna também apresentam uma série de particularidades.

O processo de tombamento de um bem deve sempre pressupor a participação da comunidade. No entanto, muitos edifícios modernos são reconhecidos como bens por especialistas, mas não pela comunidade local ou nacional. Se esses edifícios estão sob o risco de destruição ou de descaracterização, deve-se esperar até mobilizar e ganhar suporte da comunidade ou se deve partir para o tombamento sem o apoio necessário? Em muitos países, faz-se necessária uma ação mais enérgica de tombamento, mesmo sob título provisório, para garantir a salvaguarda desses bens.

A arquitetura moderna está pouco presente nos centros urbanos, mas sim escondida em subúrbios e áreas periféricas ou mesmo rurais. Não são obras fáceis de ser vistas e vivenciadas por um público mais amplo. Como Richard Longstreth advertiu, "o grande problema é que nós não conseguimos ver grandes marcos da arquitetura moderna, não conseguimos apreendê-los de um ponto de vista único ou monumental" (LONGSTRETH, 1995, p. i; 16). Alguns dos melhores exemplos de residências modernas encontram-se em áreas rurais, como nos casos de muitas casas norte-americanas, ou escondidas em subúrbios de São Paulo, Cidade do México ou Los Angeles.

Outro problema, indicado por Andrew Saint, é que simplesmente existe um número muito maior de edifícios modernos do que de épocas anteriores. Quase todo o sistema de conservação existente está voltado não para a beleza mas para a raridade, ou seja, simples edifícios do século 18 ou 19 são tombados por que são 
daqueles séculos, enquanto edifícios muito mais significativos do século 20 ainda esperam o tombamento (SAINT, 2007, p. 16-17; CANTACUZINO, 2003, p. 53; JANHENKET, 1998, p. 14; ALLAN, 2007, p. 17; PRUDON, 2008, p. 157-158). Nós protegemos de preferência os edifícios mais distantes no tempo e os protegemos menos quanto mais eles se aproximam de nossa época. Além disso, existe uma documentação ainda disponível sobre o projeto, construção e história dessas obras, pois, além das plantas, muitos dos arquitetos, construtores e usuários ainda estão vivos e podem disponibilizar importantes informações. Isto é algo positivo em termos de um intervenção, mas torna o processo de avaliação mais longo e custoso.

A questão da avaliação da significância do edifício parece ser crucial para a conservação da arquitetura de nosso passado recente, não apenas para aqueles envolvidos com a conservação de grandes obras-primas, mas também para aqueles que lidam com os edifícios modernos no dia a dia. Já que os valores da arquitetura moderna ainda não estão claramente reconhecidos pela sociedade, essas incertezas são aparentes no resultado das intervenções. Programas educacionais e campanhas públicas fazem-se necessários para se conseguir a conscientização de uma sociedade sobre a necessidade de se protegerem essas obras.

Avaliar a significância de um edifício é algo que requer certa distância no tempo (JOKILEHTO, 2003, p. 108). Como grande parte de nosso ambiente do dia a dia é o resultado direto ou indireto da modernidade, nós temos dificuldade para avaliar sua significância. $O$ mundo moderno está à nossa volta e as pessoas resistem a reconhecer como significativos edifícios ou paisagens nos quais elas nasceram ou cresceram.

A amplitude da arquitetura moderna também traz desafios para a noção de tombamento. Uma estratégia mais ampla precisa ser elaborada para lidar com a complexidade e a escala da arquitetura do século 20, que inclui edifícios em altura, campi universitários, fábricas e casas estandardizadas. 


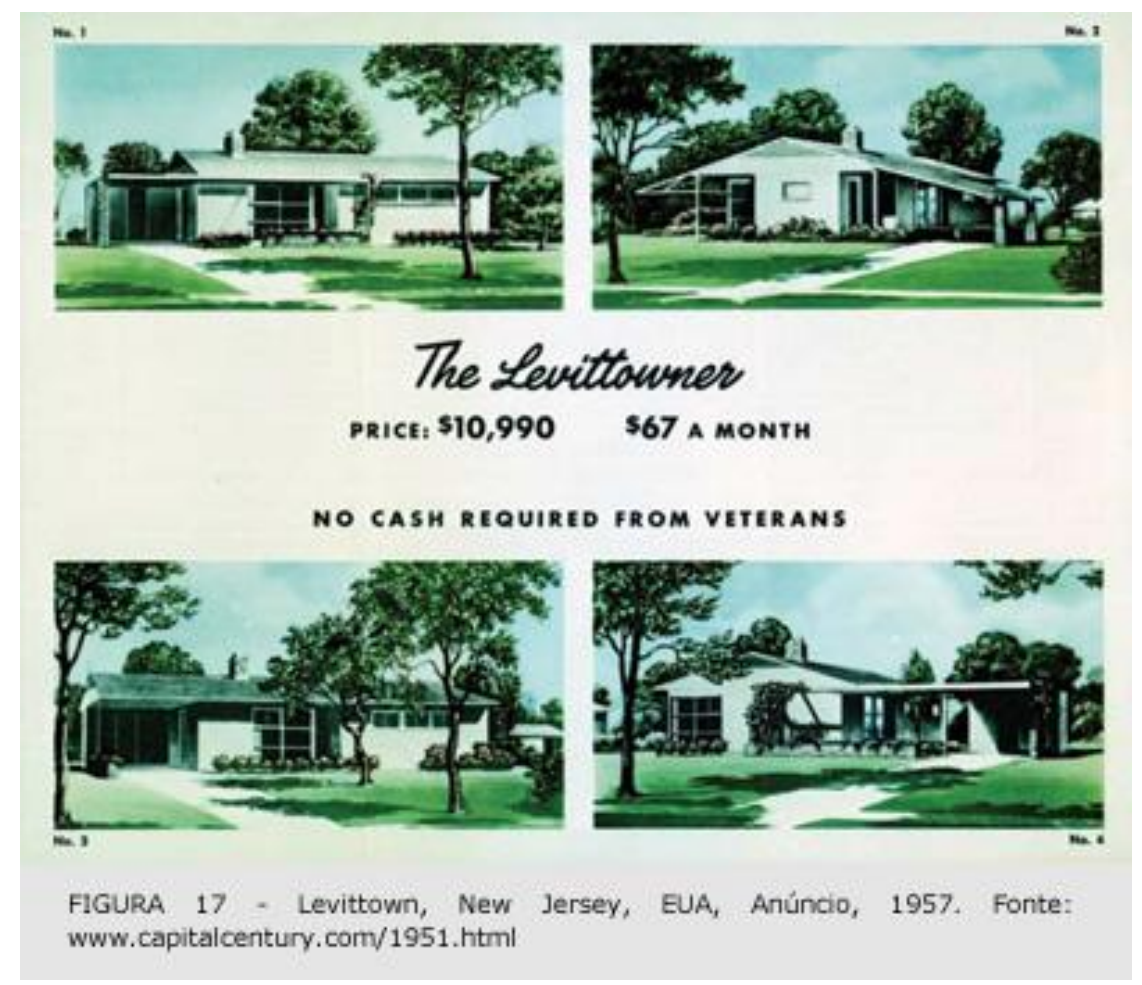

O caso norte-americano é exemplar nesse sentido. As casas estandardizadas norteamericanas são símbolos legítimos da engenhosidade humana de prover soluções para o sonho da casa própria (SAVAGE; SCHULL, 1995, p. 4). Esses modelos de casas produzidas em série merecem ser tombados? Se sim, apenas um, alguns ou todos? Como podemos tombar um grande conjunto suburbano de habitação em massa? Da mesma forma, os primeiros postos de gasolina, shopping centers e fastfoods e outros exemplos de roadside architecture devem ser tombados? Geralmente, eles são vistos como pragas na paisagem, longe de qualquer valor histórico. Entretanto, este tipo de arquitetura e de paisagem foi o resultado de uma política de provimento de habitações e mobilidade por meio do automóvel em uma escala nunca vista antes, algo marcante do século 20 (SAVAGE; SCHULL, 1995, p. 13; LONGSTRETH, 1995, p. i; 18). É preciso fazer um esforço para entender como esse ambiente se formou e encontrar elementos significativos que devem ser guardados para as futuras gerações.

\section{Conclusões}

A arquitetura moderna é uma parte fundamental do patrimônio cultural do século 20 e, como tal, necessita ser preservada para as novas gerações. A conservação da arquitetura moderna acarreta, como vimos, uma série de desafios, que estão 
relacionados aos aspectos internos, inerentes à fábrica do edifício (seus materiais e sistemas), e externos (falta de manutenção, não aceitação da pátina, não reconhecimento e mudanças de uso). Esses desafios trazem novos temas para reflexão, mas, a nosso ver, não invalidam o arcabouço teórico da disciplina da conservação.

Um desses temas é, sem dúvida, a questão da autenticidade. Na teoria da conservação, a autenticidade é tradicionalmente ligada à materialidade do edifício, e sempre se relaciona com o material e com a noção de verdade. As intervenções de conservação sempre tentaram manter ao máximo a autenticidade material do edifício.

Os valores da arquitetura moderna, entretanto, residem não apenas em sua materialidade, mas sobretudo na forma como esses materiais são articulados na criação do espaço. Articulações mais dinâmicas entre cômodos e espaços, por meio de estratégias como transparência, promenade architecturale e multiplicidade de pontos de vistas, a interpenetração entre interior e exterior e relações mais sutis com a paisagem, entre outros, são intenções projetuais consideradas como valores centrais para a aquitetura moderna. Como foi visto, algumas obras-primas tiveram sua fábrica refeita, para que fossem mantidas as intenções projetuais originais. Entretanto, estes valores não são ainda reconhecidos pelo grande público e nem mesmo por parte da comunidade de conservadores.

As principais cartas patrimoniais da década de 1990, a Carta de Nara (1994) e a última revisão da Carta de Burra (1999) ampliaram os parâmetros e convenções da disciplina da conservação. A Carta de Nara reafirmou a importância do conceito de autenticidade, mas ampliou-o para além da materialidade, incluindo técnicas artesanais e práticas culturais. Da mesma forma, a Carta de Burra ao adotar critérios mais amplos para a definição de significância cultural, expandiu a noção de patrimônio cultural. Esta aceitação do intangível em detrimento da materialidade abriu novas possibilidades para a conservação da arquitetura moderna.

Dada a importância das intenções projetuais na arquitetura, elas devem ser preservadas para as futuras gerações. O fato de termos mais registros, fotos, 
plantas do projeto original e do edifício em seus primeiros anos, além da presença dos próprios arquitetos, construtores ou primeiros usuários, possibilita a identificação destas estratégias projetuais. Além disso, o desuso dos materiais tradicionais e a rápida obsolescência dos materiais oriundos da produção industrial que era interrompida poucos anos após seu uso, dificultaram o restauro com os materiais e técnicas originais e reforçaram a intenção projetual.

Por outro lado, o privilegiamento da intenção projetual pode nos levar a uma arriscada postura violletiana de fazer reconstruções de um estado imaginário que nunca existiu e a remover todos os elementos materiais. Na conservação da arquitetura moderna, é preciso encontrar um equilíbrio entre a autenticidade do espaço e o respeito pela autenticidade material.

\section{Referências bibliográficas}

ALLAN, John. Conservation of modern buildings: a practitioner's view. In: MACDONALD, Susan (Ed.). Modern matters: principles and practice of conserving recent architecture. Shaftesbury: Donhead, 1996. p. 123-128.

ALLAN, John. Points of balance: patterns of practice in the conservation of modern architecture. In: MACDONALD, Susan; NORMANDIN, Kyle; KINDRED, Bob (Ed.). Conservation of modern architecture. Shaftesbury: Donhead, 2007. p. 13-46.

BARDELLI, Pier Giovanni; FILIPPI, Elena; GARDA, Emilia (Ed.). Curare il moderno: i modi della tecnologia. Veneza: Marsilio, 2002.

BENJAMIN, Walter. Paris, the capital of the $19^{\text {th }}$ Century. In: CHARLES Baudelaire: a lyric poet in the era of the high capitalism. London: NLB, 1973. p. 11-16.

BENJAMIN, Walter. Teses sobre o conceito de história. In: OBRAS escolhidas. São Paulo: Brasiliense, 1985. p. 222-234. v. 1.

BENJAMIN, Walter. The arcades project. Cambridge: Belknap/Harvard, 1999.

BERMAN, Marshall. Tudo que é sólido se desmancha no ar: a aventura da modernidade. São Paulo: Companhia das Letras, 1987.

BISCONTIN, Guido; DRIUSSI, Guido (Ed.). Architettura e materiali del Novecento: conservazione, restauro, manutenzione. Veneza: Edizioni Arcadia Ricerche, 2004. Atti del convegno di studi, Bressanone, 13-16 luglio 2004. 
BURKE, Sheridan. ICOMOS $20^{\text {th }}$ Century Heritage International Scientific Committee. In: MACDONALD, Susan; NORMANDIN, Kyle; KINDRED, Bob (Ed.). Conservation of modern architecture. Shaftesbury: Donhead, 2007. p. 143-150.

CANTACUZINO, Sherban. Community building and representation. In: OERS, R.V.; HARAGUCHI, S. (Ed.). World Heritage papers, 5 Identification and documentation of modern heritage. Paris: UNESCO/WHC, 2003. p. 52-59.

CUNNINGHAM, Allen (Ed.). Modern movement heritage. London: E\&FN Spon, 1998.

DE JONGE, Wessel. Campaign for Zonnestraal. Docomomo Journal, n. 11, p. 6, Jun 1994.

DE JONGE, Wessel. Early modern architecture: how to prolong a limited life-span? In: SLATON, Deborah; SHIFFER, Rebecca (Ed.). Preserving the recent past. Washington, D.C.: Historic Preservation Education Foundation, 1995. p. iv-3, iv-9.

DE JONGE, Wessel. Restauration du béton et authenticité des matériaux: quelques exemples européens. Monumental, n. 16, p. 28-35, 1997.

DE JONGE, Wessel. Zonnestraal Sanatorium, Hilversum. In: CUNNINGHAM, Allen (Ed.). Modern movement heritage. London: E\&FN Spon, 1998. p. 149-158.

DONZET, André-Jean. Notre-Dame du Raincy. Monuments historiques, n. 140, p. 69-71, 1985.

HEYNEN, Hilde. Transitoriness of modern architecture. In: CUNNINGHAM, Allen (Ed.). Modern movement heritage. London: E\&FN Spon, 1998. p. 29-35.

JAN-HENKET, Hubert. The icon and the ordinary. In: CUNNINGHAM, Allen (Ed.). Modern movement heritage. London: E\&FN Spon, 1998. p. 13-17.

JOKILEHTO, Jukka. Continuity and change in recent heritage. In: OERS, R.V.; HARAGUCHI, S. (Ed.). World Heritage papers, 5 Identification and documentation of modern heritage. Paris: UNESCO/WHC, 2003. p. 101-109.

LEATHERBARROW, David; MOSTAFAVI, Mohsen. On Weathering: the Life of buildings in time. Cambridge: The MIT Press, 1997.

LINDH, Tommi. International style, international problems. In: KERVANTO-NEVANLINNA, Anja (Ed.). Dangerous liaisons. Preserving post-war modernism in city centers. Helsinki: Icomos Finnish National Committee, 2001.

LONGSTRETH, Richard. I can't see it, I can't understand it and it doesn't look old for me. In: SLATON, Deborah; SHIFFER, Rebecca (Ed.). Preserving the recent past. Washington, D.C.: Historic Preservation Education Foundation, 1995. p. i; 15-19.

MACDONALD, Susan. Reconciling authenticity and repair in the conservation of modern architecture. Journal of Architectural Conservation, v. 2, n. 1, p. 36-54, March 1996. 
MACDONALD, Susan (Ed.). Modern matters: principles and practice of conserving recent architecture. Shaftesbury: Donhead, 1996.

MACDONALD, Susan. Defining an approach: a methodology for the repair of post-war buildings. In: (Ed.). Preserving post-war heritage: the care and conservation of mid-twentieth century architecture. London: Donhead, 2001. p. 32-40.

MACDONALD, Susan. $20^{\text {th }}$ century heritage: recognition, protection and practical challenges. In: ICOMOS World Report 2002-2003 on monuments and sites in danger. Paris: ICOMOS, 2003.

MACDONALD, Susan; NORMANDIN, Kyle; KINDRED, Bob (Ed.). Conservation of modern architecture. Shaftesbury: Donhead, 2007.

MAXWELL, Robert. Preface. In: CUNNINGHAM, Allen (Ed.). Modern movement heritage. London: E\&FN Spon, 1998.

MOREIRA, Fernando; NASLAVSKY, Guilah. Conservação e requalificação de grandes conjuntos habitacionais modernistas: reflexões sobre a experiência escandinava recente. In: SEMINÁRIO DOCOMOMO BRASIL, 3., 2007, Porto Alegre. O Moderno já passado/O passado no moderno: [anais]. Porto Alegre: Propar-UFRGS, 2007. CD-ROM.

MOUTON, Benjamin. Restauration de l'église du Raincy. Monumental, n. 16, p. 60-65, 1997.

PAWLEY, Martin. Terminal architecture. London: Reaktion Books, 1993.

PARKES, Jeff. Towards the fully integrated building: servicing post-war building. In: MACDONALD, Susan (Ed.). Preserving post-war heritage: the care and conservation of mid-twentieth century architecture. London: Donhead, 2001. p. 41-47.

POWERS, Alan. Style or substance: what are we trying to conserve?. In: MACDONALD, Susan (Ed.). Preserving post-war heritage: the care and conservation of mid-twentieth century architecture. London: Donhead, 2001. p. 37.

PROJETOS e obras de recuperação da Igreja da Pampulha. In: CASTRO, Mariangela; FINGUERUT, Silvia (Org.). Igreja da Pampulha: restauro e reflexões. Rio de Janeiro: Fundação Roberto Marinho, 2006. p. 20-23.

PRUDON, Theodore. Great expectations: Woolworth Building (Cass Gilbert) and Lever House (SOM). In: CUNNINGHAM, Allen (Ed.). Modern movement heritage. London: E\&FN Spon, 1998. p. 88-95.

PRUDON, Theodore. Preservation of modern architecture. New York: John Wiley, 2008.

SANT'ELIA, Antonio. Futurist architecture. In: CONRADS, Ulrich (Ed.). Program and manifestoes on 20th century architecture. Cambridge: The MIT Press, 1999. p. 35-38. 
SAINT, Andrew. Philosophical principles of modern conservation. In: Macdonald, Susan (Ed.). Modern matters. London: Donhead, 1996. p. 15-28.

SAVAGE, Beth; SCHULL, Carol. Trends in recognizing places for significance in the recent past. In: SLATON, Deborah; SHIFFER, Rebecca (Ed.). Preserving the recent past. Washington, D.C.: Historic Preservation Education Foundation, 1995. p. ii; 3-14.

SLATON, Deborah; SHIFFER, Rebecca, editors. Preserving the recent past. Washington, D.C.: Historic Preservation Education Foundation, 1995.

SLATON, Deborah, FOULKS, William (Ed.). Preserving the recent past 2. Washington,D.C.: National Park Service; Historic Preservation Education Foundation, 2000.

STRATTON, Michael (Ed.). Structure and style: conserving twentieth century buildings. London: E \& FN Spon, 1997.

\section{Crédito}

* Arquiteto pela Universidade Federal de Pernambuco (UFPE) (1990), Ph.D. em arquitetura pela University of Pennsylvania (2004), professor do Programa de Pós-Graduação em Desenvolvimento Urbano da UFPE e diretor-geral do Centro Avançados de Estudos da Conservação Integrada (CECI) e-mail: fmoreira@hotlink.com.br

Esse texto foi resultado de uma pesquisa realizada no ICCROM - International Centre for the Study of Preservation and Restauration of Cultural Properties, por meio de uma fellowship oferecida por este órgão e com o apoio financeiro do CNPq - Conselho Nacional de Desenvolvimento Científico e Tecnológico, em 2008. O autor agradece o apoio financeiro do ICCROM e do CNPq.

artigo recebido em $04 / 10$

artigo aprovado em 10/10 